\title{
Reactive Oxygen Species (ROS): Beneficial Companions of Plants' Developmental Processes
}

\author{
Rachana Singh ${ }^{1 \dagger}$, Samiksha Singh ${ }^{1+}$, Parul Parihar ${ }^{1}$, Rohit K. Mishra ${ }^{1}$, \\ Durgesh K. Tripathi ${ }^{2}$, Vijay P. Singh ${ }^{3 *}$, Devendra K. Chauhan ${ }^{2}$ and Sheo M. Prasad ${ }^{*}$ \\ ${ }^{1}$ Ranjan Plant Physiology and Biochemistry Laboratory, Department of Botany, University of Allahabad, Allahabad, India, \\ ${ }^{2}$ DD Pant Interdisciplinary Research Laboratory, Department of Botany, University of Allahabad, Allahabad, India, \\ ${ }^{3}$ Government Ramanuj Pratap Singhdev Post Graduate College, Baikunthpur, India
}

OPEN ACCESS

Edited by:

Mirza Hasanuzzaman, Sher-e-Bangla Agricultural University,

Bangladesh

Reviewed by:

Luis E. Hernandez,

Autonomous University of Madrid,

Spain

Dibyendu Talukdar

ROPMC, India

*Correspondence:

Vijay P. Singh

vijaypratap.au@gmail.com

Sheo M. Prasad

profsmprasad@gmail.com

tThese authors have contributed equally to this work.

Specialty section:

This article was submitted to

Plant Physiology,

a section of the journal

Frontiers in Plant Science

Received: 15 January 2016

Accepted: 15 August 2016 Published: 27 September 2016

Citation:

Singh $R$, Singh S, Parihar $P$, Mishra RK, Tripathi DK, Singh VP,

Chauhan DK and Prasad SM (2016) Reactive Oxygen Species (ROS): Beneficial Companions of Plants

Developmental Processes.

Front. Plant Sci. 7:1299.

doi: 10.3389/fpls.2016.01299
Reactive oxygen species (ROS) are generated inevitably in the redox reactions of plants, including respiration and photosynthesis. In earlier studies, ROS were considered as toxic by-products of aerobic pathways of the metabolism. But in recent years, concept about ROS has changed because they also participate in developmental processes of plants by acting as signaling molecules. In plants, ROS regulate many developmental processes such as cell proliferation and differentiation, programmed cell death, seed germination, gravitropism, root hair growth and pollen tube development, senescence, etc. Despite much progress, a comprehensive update of advances in the understanding of the mechanisms evoked by ROS that mediate in cell proliferation and development are fragmentry and the matter of ROS perception and the signaling cascade remains open. Therefore, keeping in view the above facts, an attempt has been made in this article to summarize the recent findings regarding updates made in the regulatory action of ROS at various plant developmental stages, which are still not well-known.

Keywords: reactive oxygen species signaling, plant growth and development, programmed cell death, seed germination, NADPH oxidases

\section{INTRODUCTION}

Life on the earth began under a reducing atmosphere. About $\sim 2.7$ billion years ago, the introduction of $\mathrm{O}_{2}$-evolving photosynthetic organisms led to an accumulation of $\mathrm{O}_{2}$ that changed the reducing environment into an oxidized one. Since then, reactive oxygen species (ROS) have been unavoidable companions of aerobic life (Gill and Tuteja, 2010; Bhattacharjee, 2012). Electron transport systems (ETCs) generally produce ROS by virtue of $\mathrm{O}_{2}$ being a powerful electron acceptor. ROS such as superoxide radical $\left(\mathrm{O}_{2}^{\bullet}\right)$, hydroxyl radical $\left({ }^{\bullet} \mathrm{OH}\right)$, hydrogen peroxide $\left(\mathrm{H}_{2} \mathrm{O}_{2}\right)$ and singlet oxygen $\left({ }^{1} \mathrm{O}_{2}\right)$ are either the product of oxidation-reduction (redox) reactions, or activated derivatives of $\mathrm{O}_{2}$, continually generated in chloroplasts, mitochondria, peroxisomes, and glyoxysomes (Sharma et al., 2012; Suzuki et al., 2012; Sandalio et al., 2013; Singh et al., 2015a,b), and also in the cytosol, apoplast, nucleus, and, endomembrane systems (Gechev et al., 2006; Ashtamker et al., 2007). These ROS are highly reactive and toxic, causing oxidative damage to macromolecules such as lipids, proteins, and nucleic acids (Karuppanapandian et al., 2011; Kapoor et al., 2015; Prasad et al., 2015). In photosynthetic tissues (leaves), chloroplasts are the major sources of ROS generation in plants (Asada, 2006; Dietz, 2016; Takagi et al., 2016; Figure 1; Table 1). Photosynthetic electron transfer chains of chloroplast produce high amounts 


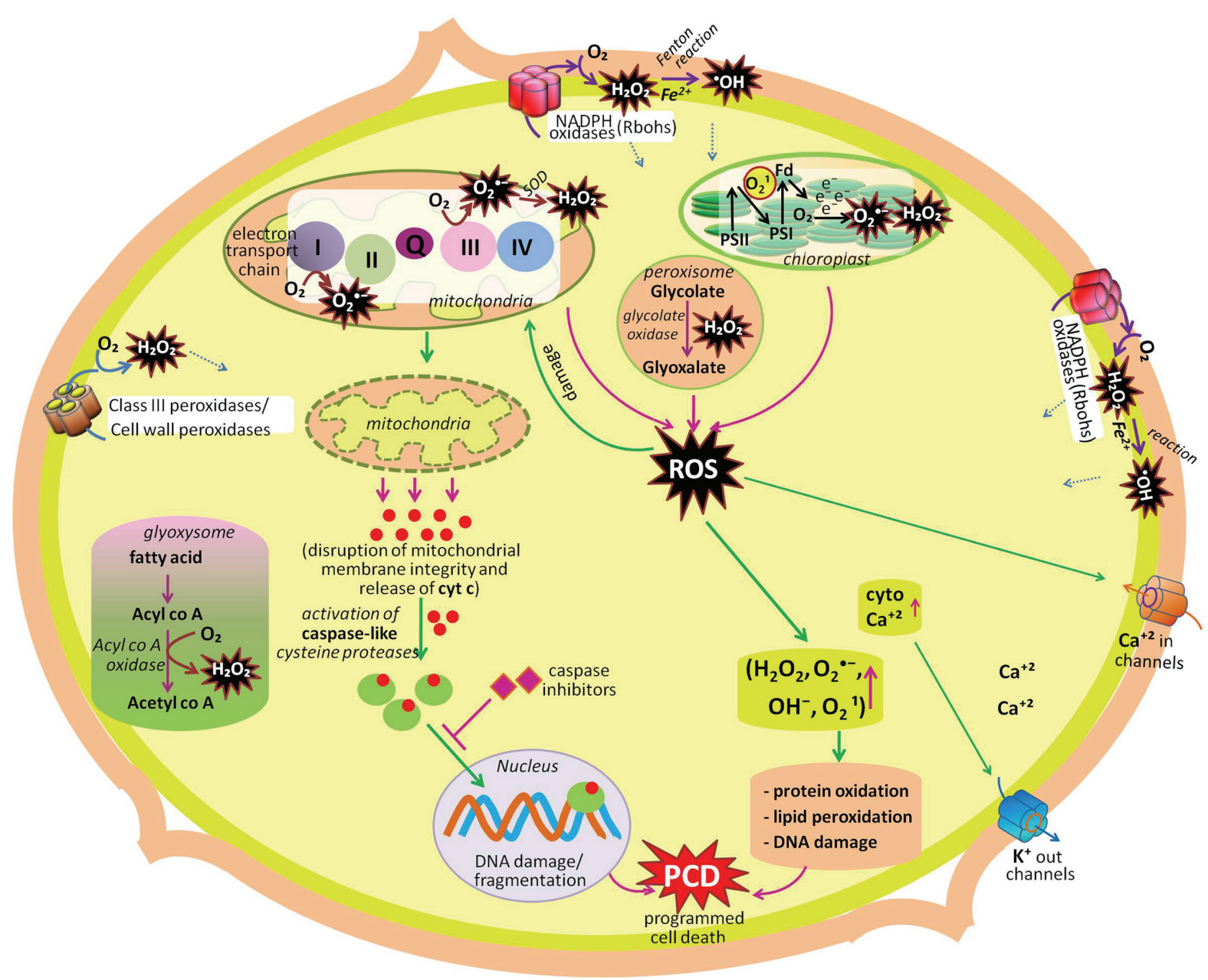

FIGURE 1 | Summary of production and metabolic fate of various ROS (hydrogen peroxide, superoxide radical, singlet oxygen, hydroxyl radical) in different cellular compartments (cell wall, chloroplast, mitochondria, peroxisome, glyoxysome, cytosol, plasma membrane). Among these organelles, chloroplast, mitochondria, peroxisome, and plasma membrane actively participate in developmental programmed cell death (dPCD). Another organelles mentioned in the figure participates in other developmental process of the plant like seed germination, cell proliferation and differentiation, polar cell growth in root hairs and pollen tube, leaf development, etc. (modified after Gadjev et al., 2008; Mittler and Blumwald, 2010; Mittler et al., 2011; Petrov et al., 2015).

of $\mathrm{O}_{2}^{\bullet}$ - (through leakage of electrons from the acceptor side of photosystem II to $\mathrm{O}_{2}$, from $\mathrm{Fe}-\mathrm{S}$ centers of photosystem I and reduced ferredoxin (Mehler reaction; Pospisil, 2012), while in non-photosynthetic tissues of plants (i.e., roots, meristems, or seeds) mitochondria are the biggest sources of ROS generation (Navrot et al., 2007; Kalogeris et al., 2014; Huang et al., 2016). In mitochondria, the key sources of ROS production are $\mathrm{NADH}$ dehydrogenase complexes I and III, and the ubiquinone pool (Marchi et al., 2012; Steffens, 2014) where $\mathrm{O}_{2}^{\bullet}-$ radicals are generated from the complexes as a by product of energy metabolism by the reduction state of ubiquinone pool (Rhoads et al., 2006; Drose and Brandt, 2012). Other sources of ROS, mainly in non-photosynthetic tissues are NADPH oxidases, cell wall peroxidases, peroxisomes, and glyoxysomes. In glyoxysomes and peroxisomes, $\mathrm{H}_{2} \mathrm{O}_{2}$ is produced during fatty acid oxidation (by Acyl CoA oxidase), and photorespiration (by glycolate oxidase), respectively (del Rio et al., 2006; Gilroy et al., 2016; Kerchev et al., 2016; RodríguezSerrano et al., 2016). In chloroplasts, during impairment of $\mathrm{CO}_{2}$ fixation, an increased activity of ribulose-1,5-bisphosphate carboxylase/oxygenase leads to the formation of glycolate, which moves to peroxisomes and leads to the formation of $\mathrm{H}_{2} \mathrm{O}_{2}$, via its oxidation in the presence of glycolate oxidase enzyme (Figure 1; Table 1). Cell wall-associated extracellular peroxidases and plasma membrane-bound NADPH oxidases (e.g., Nox, Rbohs or respiratory burst oxidase homologs) are the key enzymes that produce $\mathrm{H}_{2} \mathrm{O}_{2}$ and $\mathrm{O}_{2}^{\bullet}$ - (usually rapidly dismutated to $\mathrm{H}_{2} \mathrm{O}_{2}$ ) in the apoplast (Bindschedler et al., 2006; Sagi and Fluhr, 2006; Choi et al., 2007). In Arabidopsis, 10 genes encoding respiratory burst oxidase homologs (Rbohs, i.e., RbohA-RbohJ) have been reported (Bedard and Krause, 2007; Marino et al., 2012). Notably, in presence of redox-active metals such as $\mathrm{Fe}^{2+}$ and $\mathrm{Cu}^{+}, \mathrm{H}_{2} \mathrm{O}_{2}$ 
TABLE 1 | Various sites of ROS production and their role in growth and development of plants.

\begin{tabular}{|c|c|c|c|c|}
\hline & Sources & Cellular localization & Developmental process & Reference \\
\hline \multicolumn{5}{|l|}{ ROS } \\
\hline $\mathrm{O}_{2}^{\bullet}-$ and $\mathrm{H}_{2} \mathrm{O}_{2}$ & Electron transport chain & Mitochondria & Seed germination & Moller, 2001; Noctor et al., 2007 \\
\hline $\mathrm{O}_{2}^{\bullet}-$ and $\mathrm{H}_{2} \mathrm{O}_{2}$ & Fatty acid oxidation & Glyoxysome & Seed germination & Huang et al., 1983 \\
\hline $\mathrm{H}_{2} \mathrm{O}_{2}$ & NADPH oxidase & Plasma membrane & Seed germination & Ishibashi et al., 2010 \\
\hline $\mathrm{H}_{2} \mathrm{O}_{2}$ & & Peroxisome & Seed germination & Palma et al., 2009 \\
\hline $\mathrm{O}_{2}^{\bullet}-$ and $\mathrm{H}_{2} \mathrm{O}_{2}$ & NADPH oxidase & Plasma membrane & Root growth and root hair development & Foreman et al., 2003 \\
\hline $\mathrm{H}_{2} \mathrm{O}_{2}$ and $\mathrm{O}_{2}^{\bullet-}$ & NADPH Oxidases & Plasma membrane & Pollen tubes growth & Cárdenas et al., 2006 \\
\hline $\mathrm{H}_{2} \mathrm{O}_{2}$ & Class III peroxidases & Cell wall & Leaf development & Lu et al., 2014 \\
\hline \multicolumn{5}{|l|}{ dPCD } \\
\hline $\mathrm{O}_{2}^{\bullet}-$ and $\mathrm{H}_{2} \mathrm{O}_{2}$ & $\begin{array}{l}\text { Electron transport } \\
\text { Chain, NADPH oxidase }\end{array}$ & $\begin{array}{l}\text { Mitochondria, Plasma } \\
\text { membrane }\end{array}$ & Self-incompatibility in pollen & Wang and Zhang, 2011; Wang et al., 2013 \\
\hline $\mathrm{O}_{2}^{\bullet}-$ and $\mathrm{H}_{2} \mathrm{O}_{2}$ & NADPH oxidase & Plasma membrane & Synergid cells dPCD & Duan et al., 2010, 2014 \\
\hline $\mathrm{H}_{2} \mathrm{O}_{2}$ & NADPH oxidase & Plasma membrane & Tapetal dPCD & Xie et al., 2014 \\
\hline $\mathrm{O}_{2}^{\bullet}-$ and $\mathrm{H}_{2} \mathrm{O}_{2}$ & NADPH oxidase & Plasma membrane & Formation of lysigenous aerenchyma & Rajhi et al., 2011 \\
\hline $\mathrm{H}_{2} \mathrm{O}_{2}$ & NADPH oxidase & Plasma membrane & Secondary wall formation (lignification) & Potikha et al., 1999 \\
\hline $\mathrm{H}_{2} \mathrm{O}_{2}$ & Electron transport chain & Chloroplast & Leaf senescence & Chen et al., 2012 \\
\hline $\mathrm{H}_{2} \mathrm{O}_{2}$ & & Peroxisome & Leaf senescence & Palma et al., 2009 \\
\hline
\end{tabular}

will give rise to highly reactive ${ }^{\bullet} \mathrm{OH}$ (the most toxic oxidant in the ROS family) or $\mathrm{O}_{2}^{\bullet}$ - via the Fenton or Haber-Weiss reactions, respectively (Jomova et al., 2010).

Parallel to the production of ROS, aerobic organisms have evolved sophisticated and well-outfitted antioxidant defense machinery. This machinery possesses highly efficient enzymatic [superoxide dismutase (SOD); ascorbate peroxidase (APX); catalase (CAT); monodehydroascorbate reductase (MDHAR); dehydroascorbate reductase (DHAR); glutathione reductase (GR); glutathione peroxidase (GPX); glutathione-S- transferase (GST); and guaiacol peroxidase (GOPX)] and non-enzymatic [ascorbic acid (ASA); glutathione (GSH); tocopherols, phenolic compounds, and non-protein amino acids] antioxidant defense systems to control over the cascades of uncontrolled oxidation (Gill and Tuteja, 2010) to detoxify ROS in order to balance the cellular ROS level, as the maintenance of redox homeostasis is essential (Singh et al., 2012a,b; Wrzaczek et al., 2013). However, disturbance in the equilibrium between ROS and antioxidant defense system creates a condition of oxidative stress.

Although early research was focused on the toxic nature of ROS, the interest has shifted over the last decade toward their emerging role as signaling molecules in a broad range of physiological processes, such as growth and development, seed germination, programmed cell death (PCD), root growth, and gravitropism (Mittler et al., 2011; Wrzaczek et al., 2013; Baxter et al., 2014). A tight balance between ROS production and scavenging is necessary for the regulatory action of ROS (de Pinto et al., 2012; Sharma et al., 2012; Baxter et al., 2014). The uses of ROS as signaling molecules indicate that plants have evolved the ability to achieve a high degree of control over ROS toxicity (Bhattacharjee, 2012; Mattila et al., 2015). In this review, we have summarized studies from past decade that have improved our understanding about roles of ROS in signaling and the regulation of cellular processes in relation to plant growth and development.

\section{CELLULAR REDOX AND SIGNAL TRANSDUCTION}

Coupled oxidation-reduction (redox) reactions in cells are the necessity of life. Various cellular signaling events are mainly based on redox reactions; therefore, it is probable that ROS are directly linked to the cellular redox metabolism. A redox regulatory network is found in each cell whose state is adjusted by ROS and these ROS regulate gene expression, translation, metabolism, and turnover (Dietz, 2016). Accordingly, cell maintains the redox homeostasis by powerful and complex antioxidants such as ascorbate and glutathione and/or antioxidant enzyme systems. Ascorbate and glutathione are much more than simple antioxidants, as they consist of both oxidizing and reducing forms. The antioxidants are principally maintained in the reduced state. A powerful reductant not only favors ROS removal but can also promote ROS generation (Foyer and Noctor, 2016). Alterations in the equilibrium of reduced $v s$. oxidized forms of the antioxidants might be used as a sensor for changes in the environment, and changes in ROS levels which might affect the redox status of the cell. Increased levels of ROS may result into the oxidation of antioxidant systems which change the redox equilibrium of the cell. According to Kleine and Leister (2016) in order to allow appropriate retrograde signaling to the nucleus, coordination of gene expression in between the compartments of the cell needs monitoring of chloroplast, glyoxysome, mitochondrial and peroxisome status. These facts imply that cells have evolved strategies to operate ROS as biological signals that control various developmental programs (Mattila et al., 2015). This explanation is based on the statement that a ROS can interact with a specific target molecule which perceives the elevated ROS concentration, and after that translates this information into a change of gene expression. These changes in transcriptional activity might be achieved by the oxidation of 
components of signaling pathways which consequently activate transcription factors (TFs) or directly by modifying a redoxsensitive TF. ROS effects on components of the mitogen activated protein kinases (MAPKs) cascade result in the indirect activation of TFs. In Arabidopsis, $\mathrm{H}_{2} \mathrm{O}_{2}$ activates Arabidopsis thaliana MPK6 (AtMPK6) and AtMAPK3 by the activity of MAPKKK Arabidopsis NPK1-RELATED PROTEIN KINASE1 (ANP1; Apel and Hirt, 2004) and strongly induces $A$. thaliana NUCLEOTIDE DIPHOSPHATE KINASE2 (AtNDPK2; Banfi et al., 2004). In a recent study, a link between the ROS-response ZAT12 zinc finger protein and iron regulation in cells was explored which suggests that the equilibrium between ROS and iron is crucial for the growth and development of plants preventing the formation of highly toxic ${ }^{\circ} \mathrm{OH}$ (Le et al., 2016). According to Le et al. (2016) ZAT12 interacts and suppresses the function of FER-LIKE IRON DEFICIENCY-INDUCED TRANSCRIPTIONFACTOR, a central regulator of iron deficiency responses. In response to elevated ROS, ZAT12 is up-regulated and suppresses iron uptake thereby preventing the risk of ${ }^{\bullet} \mathrm{OH}$ formation. Another example of biological regulatory circuit was reported by Adachi et al. (2015) who have identified a WRKY TF that is phosphorylated by MAPK and a W-box in the promoter region of Nicotiana tabacum $\mathrm{RBOH}$, interconnecting the phosphorylation events of MAPK in response to pathogen recognition with the accumulation of $\mathrm{RBOH}$ protein. Moreover, in recent years different members of the NAC family of TFs (e.g., Fang et al., 2015; Chen et al., 2016; Zhu et al., 2016), APETALA2/ethylene response TF REDOX RESPONSIVE TRANSCRIPTION FACTOR1 that are regulated by different WRKYs (Matsuo et al., 2015), and different zincfinger proteins such OXIDATIVE STRESS2 (He et al., 2016) like ROS-response regulatory proteins were identified. Besides TFs, calcium (Ca) waves comprise important components of systemic signaling in plants (e.g., Suzuki et al., 2013; Carmody et al., 2016; Choi et al., 2016; Evans et al., 2016). Several findings summarized that $\mathrm{RBOH}$ acts as a central hub in the cellular ROS-signaling network (Baxter et al., 2014; Willems et al., 2016) and this RBOH functions along with MAPK pathways to integrate ROS signals and modulate cell-to-cell signal propagation in local and systemic signaling (Evans et al., 2016; Gilroy et al., 2016). These MAPK pathways take part in retrograde signaling from the chloroplast to the nucleus (Vogel et al., 2014; Dietz, 2016). Thus, MAPK pathways are of fundamental as well as far-reaching importance in converting ROS signals into protein phosphorylation.

\section{ROLE OF ROS IN PLANT GROWTH AND DEVELOPMENT}

\section{ROS and Cell Proliferation and Differentiation: A Cascade of Signaling Network}

In multicellular organisms, growth mainly depends on the maintenance of an appropriate equilibrium between cell division and differentiation (Figure 2). In the case of animals, interruption of this equilibrium between cell division and differentiation can lead to tumoral growth and disease, while in plants; it can lead to premature cessation of organogenesis, or as a consequence of abnormal growth (Zhang et al., 2008). The initial stage of differentiation is marked by the transition from cellular proliferation to elongation, which is regulated by ROS homeostasis (Tsukagoshi et al., 2010). According to Dunand et al. (2007), $\mathrm{O}_{2}^{-}-$and $\mathrm{H}_{2} \mathrm{O}_{2}$ are two main ROS, which are differentially distributed within the root tissues of model plant Arabidopsis. $\mathrm{O}_{2}^{\bullet}$ principally accumulates in expanding meristem cells, while $\mathrm{H}_{2} \mathrm{O}_{2}$ accumulates in the elongation zone (Wells et al., 2010) and an overlap of both types of ROS is observed within the "transition zone" (Figure 2). The transition between root cell proliferation and differentiation is mainly controlled by the delicate equilibrium between $\mathrm{O}_{2}^{\bullet}-$ and $\mathrm{H}_{2} \mathrm{O}_{2}$, which in turn is regulated by a TF: UPBEAT1 (UPB1; Tsukagoshi et al., 2010). The UPB1, a member of the basic/helix loop-helix (bHLH) TF family, shows an increased expression in the root transition zone (Tsukagoshi et al., 2010). Tsukagoshi et al. (2010) have reported that plants over-expressing UPB1 had shorter roots due to a decrease in both meristem size and mature cells, while plants lacking UPB1 (upb1 mutant) had longer roots with increased meristem size and longer root cells. Furthermore, when Tsukagoshi et al. (2010) investigated the mechanism of action of UPB1 regulated genes, a set of peroxidases (Prxs) was seen to be directly repressed by UPB1. Further investigation pointed out that $\mathrm{O}_{2}^{\bullet}$ - production was reduced in lines over-expressing UPB1 but increased in the elongation zone in the upb1 mutant, while $\mathrm{H}_{2} \mathrm{O}_{2}$ was found to be increased in the plants over-expressing $\mathrm{UPB} 1$ and reduced in the elongation zone of $u p b 1$ mutant. These findings suggested that the position of the transition zone is determined by the ramp formed by $\mathrm{O}_{2}^{\bullet}-$ in the meristem to maintain the cellular proliferation, and $\mathrm{H}_{2} \mathrm{O}_{2}$ in the elongation zone, for differentiation. This indicates that UPB1, feedback of which is regulated by $\mathrm{H}_{2} \mathrm{O}_{2}$, plays a key role in maintaining the balance of $\mathrm{O}_{2}^{\bullet}$ - and $\mathrm{H}_{2} \mathrm{O}_{2}$ via its control on Prxs expression.

Genetic analysis by Sundaravelpandian et al. (2013) signifies that the subunits of the mediator complex PHYTOCHROME AND FLOWERING TIME1 (PFT1)/MED25 and MED8 are vital for the differentiation of root hairs (Figure 2). Moreover, studies have demonstrated that PFT1/MED25 restricts cell growth, while MED8 works independently of PFT1 to control organ growth and regulates ROS balance in roots (Xu and Li, 2011). Transcriptional profiling of roots of $p f t 1$ mutants disclosed that PFT1 triggers $\mathrm{H}_{2} \mathrm{O}_{2}$ formation mediated by a subset of class III peroxidase enzymes, to maintain the equilibrium between $\mathrm{H}_{2} \mathrm{O}_{2}$ and $\mathrm{O}_{2}^{\bullet}-$ during root hair differentiation. Perturbed $\mathrm{H}_{2} \mathrm{O}_{2}$ and $\mathrm{O}_{2}^{\bullet}-$ distribution was seen in $p f t 1$ mutants, suggesting that PFT1 is necessary to maintain the redox homeostasis in roots (Sundaravelpandian et al., 2013).

In the fungus Neurospora crassa, at the start of each cell differentiation step, a hyperoxidant state occurs that leads to the development of conidia (Gessler et al., 2007). According to Aguirre et al. (2005), the hyperoxidant state is transient and unstable, and occurs as ROS production exceeds the antioxidant capacity of the cell. It is well-known from this example that antioxidants inhibit developmental processes, which leads to the idea that ROS may be required for these processes in plants as well. In contrast, it is predictable that the deficiency of antioxidant 


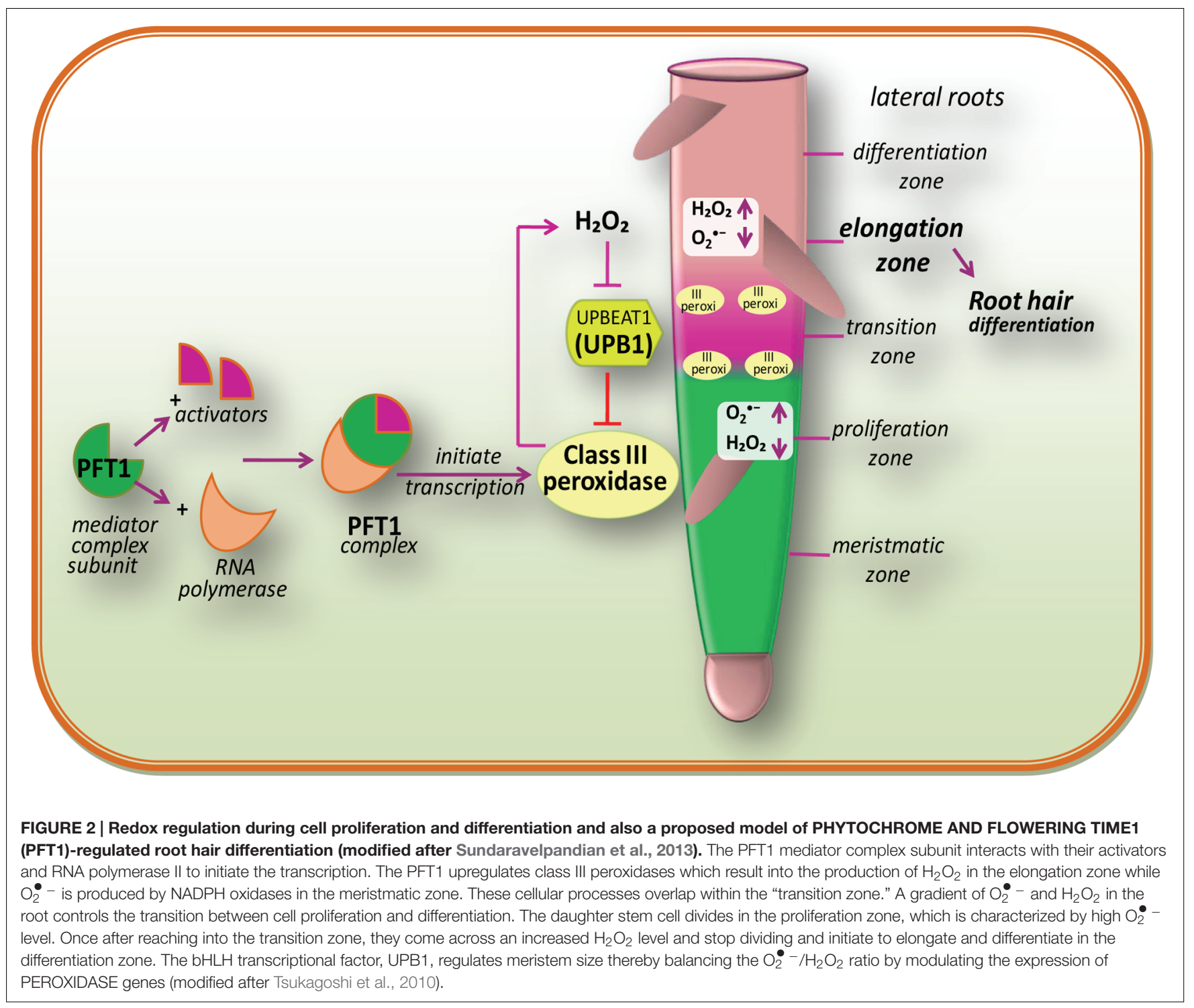

enzymes will result in to elevated ROS levels, and improved cell differentiation will take place.

\section{ROS and Programmed Cell Death (PCD): An Approach of Life for Plants}

Programmed cell death, which is critical in plant organogenesis and survival, is an integral cellular program employed by plants by which targeted cells terminate to demise under certain developmental (vegetative and reproductive) and stress conditions (Aken and Van Breusegem, 2015; Ambastha et al., 2015; Durme and Nowack, 2016). It is essential for removing unwanted diseases or damaged cells, controlling cell number and maintaining the homeostatic balance and thereby improving the endurance of organisms (Petrov et al., 2015; Singh et al., 2015).

Plant PCD is related with a number of developmental processes including embryo formation, degeneration of the aleurone layer in germinating seeds, formation of root aerenchyma and epidermal trichomes, differentiation of tracheary elements, tapetum degeneration, pollen selfincompatibility, floral organ abscission, leaf shape remodeling, and leaf senescence (Gechev et al., 2006). ROS such as $\mathrm{H}_{2} \mathrm{O}_{2}$ is identified as key modulators of PCD along with other biological processes such as growth and development (Gechev et al., 2006). Concerning developmental programmed cell death (dPCD), a division can be made between (1) differentiation induced PCD that occurs as final differentiation step in specific cell types, for instance, tracheary elements in xylem, the trichome/ root cap, or tapetum layer of anther (Plackett et al., 2011; Bollhöner et al., 2012; Fendrych et al., 2014), and (2) age-induced PCD, i.e., cells must die to form organs for appropriate functions or shapes (unisexual reproductive organs in dicots, aerenchyma tissue, leaf shape), or cells die as they accomplished their function and/or are no longer required (nectaries and petals of flowers after pollination, leaf senescence; Thomas, 2013). Nevertheless, some types of PCDs, including endosperm cell death or pollen self 
incompatibility (SI) does not fall into either of above proposed classes (van Doorn et al., 2011).

The life cycle of plant alternates between diploid sporophyte and haploid gametophyte phases. The sporophytic phase starts with zygote $(2 \mathrm{n})$ formation and ends with flower bearing adult plant while gametophytic phase starts with sporophytic meiosis and develops into male (pollen grain) and female (ovule) reproductive structures. In $\mathrm{dPCD}$, plants thereby removing tissue or organs which are no longer necessary conserve its energy along with blocking the possible entry sites for pathogens.

According to Tripathi and Tuteja (2007), to protect the initial growth of the ovule, sepals, and petals after accomplishing their role may undergo dPCD, where ROS specifically $\mathrm{H}_{2} \mathrm{O}_{2}$ is known to be involved in the death of petal cells (Tripathi and Tuteja, 2007). ROS is produced from $\mathrm{H}_{2} \mathrm{O}_{2}$ therefore, the enzymes regulating $\mathrm{H}_{2} \mathrm{O}_{2}$ level showed differential expression in dPCD during senescence (Halliwell and Gutteridge, 1989). Panavas and Rubinstein (1998) have also reported an increase in ROS due to increased SOD and decreased CAT activities in daylily plant that results into $\mathrm{dPCD}$.

In megaspore, the chalazal cells differentiated into the three antipodal cells and micropylar cells develop into one egg and the two synergid cells and in center of embryo two polar nuclei are present (Yadegari and Drews, 2004). The synergid cells produce signals which attract and guide the pollen tube growth, ultimately deteriorate in a programmed manner (Punwani et al., 2007). In A. thaliana, FERONIA (FER) receptor kinase is responsible for the production of ROS by NADPH oxidase via ROP small GTPase in synergid cells (Duan et al., 2010, 2014) leading to dPCD. ROS by activating $\mathrm{Ca}^{2+}$-permeable channels alter the cell wall extensibility. In A. thaliana, ROS production (necessary for pollen tube growth) by the pollen-specific NADPH oxidases: RbohH and RbohJ is mediated by ANX, which maintains a tip-focused $\mathrm{Ca}^{2+}$ gradient (Boisson-Dernier et al., 2013; Kaya et al., 2014; Lassig et al., 2014). The excess $\mathrm{Ca}^{2+}$ influx might be the reason of ROS-induced pollen tube rupturation/PCD (Duan et al., 2014). Likewise, synergid-derived ZmES4, a defensin-like peptide by opening the $\mathrm{K}^{+}$channel induced rapid pollen tube rupturation in maize (Amien et al., 2010). These findings revealed that ROS and other secreted proteins regulate cell wall alteration for the reception of pollen tube through the functions of FER in synergid cells and ANX in pollen tubes. On the opposite end of the ovule, three antipodal cells undergo dPCD immediately before fertilization in mature embryo sacs of $A$. thaliana. It is reported that lifespan of antipodal cell is regulated by central cell so; ROS accumulation specifically in the mitochondria of the central cell might act as a signal in dPCD of antipodal cell in a non-cell autonomous way (Hayashi et al., 2001).

During development of male sex organs, ROS signatures dictate the correct timing of tapetal $\mathrm{APCD}$ because in order to release pollen, tapetum cells must die (Hautegem et al., 2015; Durme and Nowack, 2016). In tapetal dPCD, $\mathrm{H}_{2} \mathrm{O}_{2}$ acts as a key regulator. In $A$. thaliana RBOHE, a tissue-specific NADPH oxidase is the major $\mathrm{H}_{2} \mathrm{O}_{2}$ contributor supporting tapetal cell death (Xie et al., 2014). According to Xie et al. (2014) both overexpression and deficiency of RBOHE eliminated usual ROS accumulation leading to the male sterility.
ROS also play a signaling role during self-incompatibility(SI; to prevent inbreeding by the rejection of incompatible pollen) induced pollen PCD in Papaver. According to Wilkins et al. (2011), the simultaneous scavenging of $\mathrm{H}_{2} \mathrm{O}_{2}$ and $\mathrm{NO}$ suppressed SI PCD (Wilkins et al., 2011). SI leads into signal transduction that involves increased ROS, $\mathrm{Ca}^{2+}, \mathrm{NO}$, activation of MAPK, and protein phosphorylation as it is supported by large number of evidences that ROS play a key role in SI response that activates $\mathrm{APCD}$ in self-compatible pollen (Bosch et al., 2010; Wilkins et al., 2011; Serrano et al., 2012; Jiang et al., 2014). In poppy, SI is associated with ROS induced activation of $\mathrm{Ca}^{2+}$ signaling cascade followed by a release of mitochondrial cytochrome $c$ into the cytosol and caspase-3-like enzyme activity (Bosch and Franklin-Tong, 2007), and process is mediated by the activity of MAPK cascade signaling (Li et al., 2006; Figure 1). According to Wilkins et al. $(2011,2015) \mathrm{Ca}^{2+}$ influx boosts $\mathrm{H}_{2} \mathrm{O}_{2}$ levels to SI-inducing levels that finally triggered a signaling network leading PCD thereby ensuring that fertilization is not achieved by incompatible pollen.

During pollination, when stigma is receptive (ready to receive pollen grains), accumulates high $\mathrm{H}_{2} \mathrm{O}_{2}$ levels, and that $\mathrm{H}_{2} \mathrm{O}_{2}$ levels decrease when stigma starts to support pollen development (Zafra et al., 2010; Serrano and Olmedilla, 2012; Serrano et al., 2012). After that, the signal exchanges in between the stigma and the pollen, that might regulate the production of ROS and reactive nitrogen species (RNS) in both tissues (Serrano et al., 2012) takes place. The $\mathrm{H}_{2} \mathrm{O}_{2}$ level in the stigma which was increased before pollination was found decreased after pollen arrival. Contrary to this, the $\mathrm{O}_{2}^{\bullet-}$ and NO levels were increased with attendant increase in peroxynitrite $\left(\mathrm{ONOO}^{-}\right.$; Serrano et al., 2015). Treatment with $\mathrm{ONOO}^{-}$scavengers decreases papillar cell death and also reduces the quantity of pollen grains deploying dPCD, suggesting that ROS mediated PCD signaling takes place during incompatible pollination in the olive (Serrano et al., 2015). After enterance in female gametophyte, pollen tube discharges its content (two male gametes). Out of two male gametes, one fertilizes the binuclear central cell to form a triploid endosperm and other migrates to the egg cell (Yadegari and Drews, 2004). The endosperm functions as a storage tissue for developing embryo which after sometimes undergo ROS induced PCD mediated by abscisic acid (ABA) and ethylene.

During cereal seed germination, gibberellic acid (GA) is produced by plant embryo that activates the aleurone cells to release an amylase enzyme, which sequentially hydrolyzes and mobilizes starch from the endosperm in the seeds thereby providing energy to the embryo. After completion of germination, these aleurone cells are abolished by PCD. According to Yadegari and Drews (2004), ROS and GA play vital roles in the control and implementation of aleurone PCD (discussed in next section).

Besides embryonic development, ROS also play a key role in dPCD of vegetative parts; the development of xylem tracheary elements is one of them. Contrary to other cell type in plants, xylem tracheary elements are functionalized by PCD leading into hollow cell cadavers with merely a remaining cell wall demarcating the sap conducting cylinder (Roberts and McCann, 2000). $\mathrm{H}_{2} \mathrm{O}_{2}$ by increasing cross-linking of polymers induces 
stiffening of the cell wall as growth ceases next to onset of differentiation (Hohl et al., 1995; Schopfer, 1996). Lignification in stem of Zinnia elegans L. is characterized by a burst in $\mathrm{H}_{2} \mathrm{O}_{2}$ production, which could act as a developmental signal in secondary wall differentiation (Potikha et al., 1999). This $\mathrm{H}_{2} \mathrm{O}_{2}$ may coordinate and regulate at the transcriptional level mRNAs synthesis encoding phenylalanine ammonia-lyase like lignin biosynthetic enzyme (Desikan et al., 1998), and xylem peroxidases (Wu et al., 1997) or trigger xylem differentiation thereby inducing PCD (Fukuda, 1996) and formation of secondary cell wall. The major $\mathrm{H}_{2} \mathrm{O}_{2}$ production site in the differentiating xylem is outer-face of the plasma membrane of both non-lignifying xylem parenchyma cells and differentiating thin-walled xylem cells. From their sites of production, $\mathrm{H}_{2} \mathrm{O}_{2}$ diffuses (mainly through the continuous cell wall space) to the differentiating (cells which are at the state of secondary cell wallformation) as well as differentiated xylem vessels (cells already have completed secondary cell wall formation, i.e., lignified; Ros Barceló, 2005), and $\mathrm{H}_{2} \mathrm{O}_{2}$ is thought to not limit the rate of xylem lignification (Ros Barceló, 2005). These findings strongly supported that $\mathrm{H}_{2} \mathrm{O}_{2}$, which is a key component for inducing dPCD signaling network in lignifications of xylem vessels, is mainly produced from non-lignifying xylem parenchyma cells as it is necessary for the polymerization of cinnamyl alcohols.

A similar picture has been reported in various forms of developmental cell death - formation of aerenchyma and the senescence-associated cell death. According to del Rio et al. (2006), ROS like $\mathrm{O}_{2}^{\bullet}$ - and $\mathrm{H}_{2} \mathrm{O}_{2}$ are the key coordinators of senescence (Lam, 2004). In the internodes of rice, the exogenous application of $\mathrm{H}_{2} \mathrm{O}_{2}$ promotes the formation of lysigenous aerenchyma (Steffens et al., 2011). In cortical cells of maize roots, Rajhi et al. (2011) have reported a strong up-regulation of gene encoding $\mathrm{RBOH}$, thereby suggesting that $\mathrm{RBOH}$ mediated ROS generation participates in the formation of lysigenous aerenchyma.

In many plants, trichomes in their fully differentiated stage are dead. The development of trichome trails a switch from mitosis to endoreduplication, branching of cells, expansion, and ultimate cell death initiated by $\mathrm{H}_{2} \mathrm{O}_{2}$ burst (Hulskamp, 2004). In trichomes of succinic semialdehyde dehydrogenase (key enzyme of $\gamma$-aminobutyrate metabolic pathway) knockout plants, enhanced $\mathrm{H}_{2} \mathrm{O}_{2}$ levels are observed (Bouche et al., 2003). In the stem nodes of rice plants, the epidermal cells that cover the primordia of adventitious roots undergo cell death before the emergence of adventitious root. Ethylene promotes epidermal cell death, which is mediated by an excess $\mathrm{H}_{2} \mathrm{O}_{2}$ production (Steffens and Sauter, 2009). In rice plant, a non-enzymatic $\mathrm{H}_{2} \mathrm{O}_{2}$ scavenger metallothionein $M T 2 b$ when downregulates it promotes ROS level in cell (Wong et al., 2004). In case of epidermal cells, ethylene downregulates $M T 2 b$ that results into PCD thereby revealing that ethylene promotes ROS accumulation that lead to MT2b mediated cell death (Steffens and Sauter, 2009).

Significant roles of ROS have also been reported during natural course of senescence, the last step of leaf development in the life span of an annual plant (Lee et al., 2012; Springer et al., 2015). The accumulation of ROS have been suggested to be an age-associated factor that triggers leaf senescence (KhannaChopra, 2012). Foyer and Noctor (2005) proposed that ROStriggered senescence is not caused by physicochemical damage of the cell, but that these molecules (ROS formation due to leakage of electrons from ETC to $\mathrm{O}_{2}$ at the onset of senescence) behave as signals, which activate gene expression pathways leading to suicide events (Sandalio et al., 2013; Jajic et al., 2015). During cell senescence, lipid peroxidation can be activated either by lipoxygenases in some tissues, where the activity of lipoxygenase increases with increasing senescence, or by ROS (Chopra, 2012; Bhattacharjee, 2014). Therefore, it was concluded that, during senescence, lipoxygenase plays an essential role in promoting oxidative damage, in which not only stimulates lipid peroxidation but it can also form ${ }^{1} \mathrm{O}_{2}$. Vanacker et al. (2006) have also reported that in senescent leaves, $\mathrm{H}_{2} \mathrm{O}_{2}$ content increases in parallel with an increase in lipid peroxidation and protein oxidation. So it is obvious that $\mathrm{H}_{2} \mathrm{O}_{2}$ plays a crucial role in the regulation of senescence signaling.

After senescence, the resulting plant organ detaches from main plant body and the process is called abscission. In several studies, it has been reported that Prxs are regularly expressed during diverse types of abscission (Meir et al., 2006; Cai and Lashbrook, 2008).

Before discussing the role of ROS in leaf abscission, the notion should be recall that Prxs actively participate in the cell wall loosening (Schweikert et al., 2000; Schopfer et al., 2001). Sakamoto et al. (2008) demonstrated that continuous $\mathrm{H}_{2} \mathrm{O}_{2}$ production in the cell wall participates in leaf abscission signaling, which is needed to induce the expression of cellulase enzyme (the cell wall-degrading), and when this continuous $\mathrm{H}_{2} \mathrm{O}_{2}$ production was suppressed by ROS inhibitors, it inhibited the cellulase activity and consequently inhibited abscission. On the other hand, exogenous application of $\mathrm{H}_{2} \mathrm{O}_{2}$ enhanced cellulase expression and abscission therefore, signifying that $\mathrm{H}_{2} \mathrm{O}_{2}$ production is essential to induce abscission. After continuous cellulase production (induced by $\mathrm{H}_{2} \mathrm{O}_{2}$ ), enhanced $\mathrm{H}_{2} \mathrm{O}_{2}$ generation at the Abscission-Zone in the AbscissionZone-separating period was observed that might play a role in the cleavage of wall polysaccharides and loosen the cell wall (Gapper and Dolan, 2006). Therefore, a huge ROS production that probably driven by Prxs at the late stage of abscission may be associated with the cell wall degradation process.

\section{ROS in Seed Dormancy and Early Seed Germination: A Hub of Regulatory Networks}

Seed dormancy and seed germination mechanisms are essential processes in plant development, and are believed to be a part of a complex regulatory network (Figure 3). In this network, ROS are considered to be key signaling actors as reported in A. thaliana (Liu et al., 2010; Leymarie et al., 2012), barley (Ishibashi et al., 2010; Bahin et al., 2011), cress (Müller et al., 2009), wheat (Ishibashi et al., 2008), and sunflower (Oracz et al., 2007). Seed germination starts with water uptake, along with 
initiation of cell division, and ends with radicle protrusion (Holdsworth et al., 2008; Bewley et al., 2013). In dry seeds, due to highly reduced enzyme activities, ROS are probably originated from lipid peroxidation like non-enzymatic reactions that occur even at very low moisture contents (Vertucci and Farrant, 1995; McDonald, 1999). However, in hydrated seeds (that occurs following imbibition) ROS may generate from all metabolically active compartments like chloroplasts (by election transfer in photosystems), glyoxysomes (by lipid catabolism), mitochondria (via respiratory activity), peroxisomes (by purine catabolism), and plasma membranes (by NADPH oxidase; Bailly, 2004). In hydrated seeds, the continuation of respiration (in mitochondria) in imbibed seeds can lead to electron leakage because the electrons of mitochondrial electron-transfer chain (mETC) have sufficient free energy to directly reduce the $\mathrm{O}_{2}$, and this can be considered as unavoidable source of increased ROS production in mitochondria (Rhoads et al., 2006; El-MaaroufBouteau and Bailly, 2008). Due to this reason, in hydrated seeds, the mitochondrial activity is considered as major source of ROS (such as $\mathrm{H}_{2} \mathrm{O}_{2}$ ) production during germination (Noctor et al., 2007). Moreover, in hydrated seeds, ROS targets may be close or far from their production sites as the free water allows ROS (or their longer-living or movable forms like $\mathrm{H}_{2} \mathrm{O}_{2}$ ) to move and reach their targets farther from their production sites while, in dry seeds the ROS targets must be close to their production sites (Bailly et al., 2008). It has been reported that $\mathrm{H}_{2} \mathrm{O}_{2}$ is produced in the seeds of Zinnia elegans (Ogawa and Iwabuchi, 2001), maize (Hite et al., 1999), wheat (Caliskan and Cuming, 1998) and soybean (Puntarulo et al., 1988) during the early imbibitional period, and cellular responses to $\mathrm{H}_{2} \mathrm{O}_{2}$, which is the most labile ROS messenger, mostly rely on the involvement of redoxactive proteins (Foyer and Noctor, 2013), stimulation of redoxsensitive TFs that orchestrate downstream cascades (Petrov and Van Breusegem, 2012), oxidation of specific peptides (Moller and Sweetlove, 2010), and the activation of MAPKs (BarbaEspín et al., 2011). ROS produced during imbibition in different sub-cellular compartments, largely affect the expressions of various genes (Neill et al., 2002). The sub-cellular ROS interact with specific target molecules (particular for increased ROS concentration), which there translate that information by altering the gene expression (Laloi et al., 2004). Oxidation of certain components that keep on to activate TFs of the signaling pathway, or the direct modification of redox-sensitive TFs by ROS, may led to the alteration of transcriptional activity (Laloi et al., 2004).

It has been reported in several studies that during seed imbibition, ROS oxidize specific proteins for driving the germination process (Barba-Espín et al., 2011; El-MaaroufBouteau et al., 2013), or oxidize mRNAs to prevent their translation (Bazin et al., 2011).

According to El-Maarouf-Bouteau and Bailly (2008), ROS have well-recognized role in endosperm weakening, protection against pathogens, mobilization of seed reserves, and PCD in seeds. In some seeds, an endosperm covers the radical tip and acts as a mechanical barrier in radicle protrusion.

When addressing the event of seed germination and seedling establishment, it appears exceedingly relevant to consider and investigate the possible interaction between ROS and plant hormones in the process of germination, as ROS involving PCD process have been established in aleurone layer of cereal grains, which are closely related to $\mathrm{H}_{2} \mathrm{O}_{2}$ interactions with $\mathrm{GA}$ and ABA hormones (Ishibashi et al., 2013; Corbineau et al., 2014; Miransari and Smith, 2014; Figure 3). It is known that in aleurone cells of cereals, GA supports germination as well as postgermination processes, which are inhibited by ABA. Although GA downregulates the ROS scavenging enzyme activities, they are retained by ABA, which advocates a ROS link to PCD execution. In vivo, ROS can damage/oxidize/weaken the cell wall polysaccharides, activate calcium channels, $\mathrm{Ca}^{2+}$ binding proteins, MAPK cascades, and damaged cell wall polysaccharides, permit elongation of the growing radicle, which is a characteristic feature of endosperm rupturation in the aleurone layer (Müller et al., 2009; Xu et al., 2010; Barba-Espín et al., 2011; DiazVivancos et al., 2013).

These authors showed that wall polysaccharides are oxidized in vivo by the developmentally regulated action of apoplastic ${ }^{\circ} \mathrm{OH}$. The cell wall loosening is assumed to involve the enzymatic as well as non-enzymatic cleavage of structural polysaccharides (Passardi et al., 2004). The regulated action of apoplastic ${ }^{\circ} \mathrm{OH}$ radical, which is generated by Prxs and/or the Fenton reaction in the cell wall (reaction 1) of radicles and endosperm caps, is known to cause the cleavage (breakdown) of hyaluronate (Stern et al., 2007), chitosan (Tanioka et al., 1996) and pullulan-like polysaccharides (Crescenzi et al., 1997).

$$
\mathrm{Fe}^{2+}+\mathrm{H}_{2} \mathrm{O}_{2} \longrightarrow \mathrm{Fe}^{3+}+\cdot \mathrm{OH}+\mathrm{OH}^{-}
$$

The production as well as the action of ${ }^{\bullet} \mathrm{OH}$ increased during endosperm weakening and radicle elongation, and were inhibited by ABA. These outcomes were reversed by GA, representing a positive role of ${ }^{\circ} \mathrm{OH}$ in cell wall loosening during seed germination (Müller et al., 2009).

When aleurone cells are exposed to GA, $\alpha$-amylase and other hydrolytic enzymes are synthesized and secreted. Contrary to this, antioxidants (activities of CAT, APX, and SOD) suppressed the induction of amylases. While ABA acts as an antagonistic factor blocking the GA response in aleurone cells via the expression of a different set of genes- reinforcing the idea that $\mathrm{H}_{2} \mathrm{O}_{2}$ functions in $\mathrm{GA}$ and $\mathrm{ABA}$ signaling thereby regulating $\alpha$-amylase production in aleurone cells (Nonogaki, 2014).

In seeds, a majority of studies have reported that ABA suppresses ROS generation, i.e., it acts as a negative regulator during seed germination (Ishibashi et al., 2012; Ye et al., 2012) while behaves as a positive regulator of the induction of dormancy (Finkelstein et al., 2008). In presence of GA, exogenous $\mathrm{H}_{2} \mathrm{O}_{2}$ had minor effect on the degradation of primary transcriptional repressor, i.e., DELLA proteins Slender1 (SLN1) mediating GA signaling, but it supported the production of the mRNA encoding GAMyb (GA-regulated Myb TF) that acts in downstream of SLN1 protein and engages $\alpha$-amylase mRNA induction. Moreover, $\mathrm{H}_{2} \mathrm{O}_{2}$ holdbacks the production of ABA-responsive protein kinase (PKABA) mRNA, which is induced by $A B A$; the production of GAMyb mRNA is repressed by PKABA (Ishibashi et al., 2012). From these studies, 


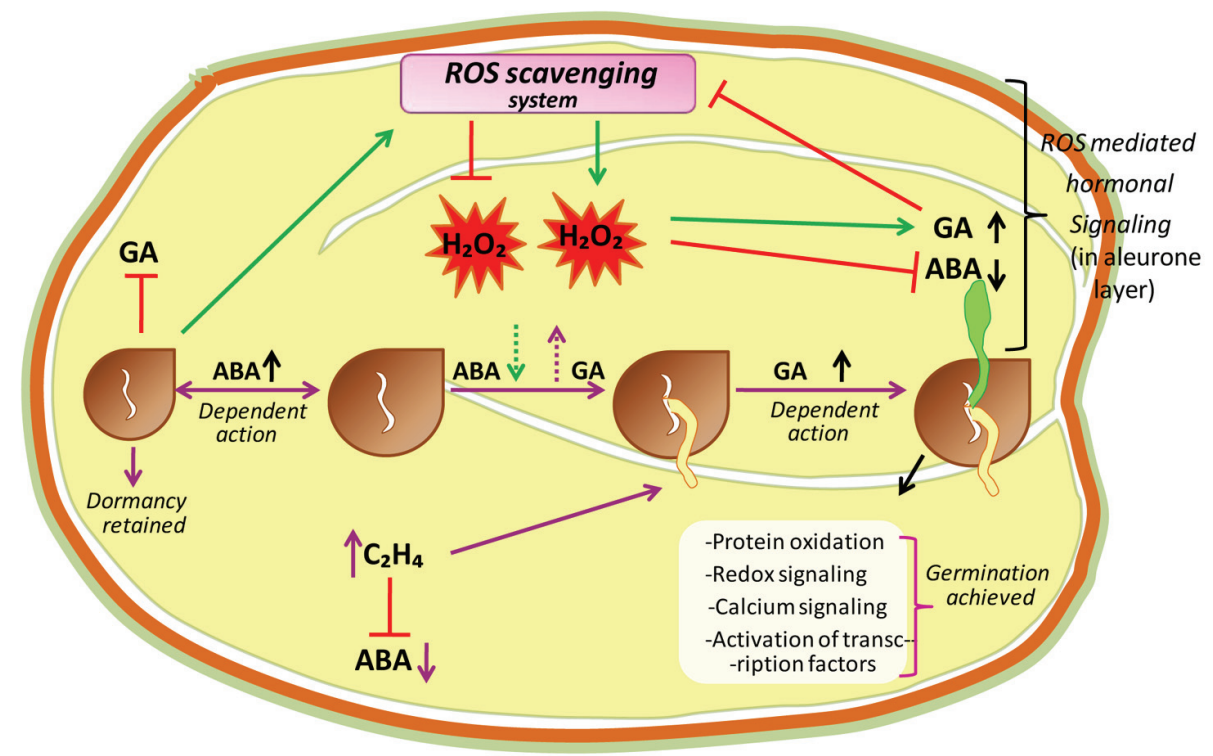

FIGURE 3 | A hypothetical model proposing central role of ROS in the mechanisms of seed dormancy release and germination. The ROS core plays a central in the regulation of germination through the crosstalk with abscissic acid (ABA) and ethylene $\left(\mathrm{C}_{2} \mathrm{H}_{4}\right)$. In dormant state, high amount of $\mathrm{ABA}$ maintains dormancy by inducing an active signaling pathway. In non-dormant seeds, $A B A$ concentration lowered which is associated with higher ROS level. Apparently $\mathrm{H}_{2} \mathrm{O}_{2}$, which could in turn interfere with ABA and GA signaling pathways, modify redox status and induce protein oxidation, redox signaling, calcium signaling and transcriptional factor activation leading to the germination of seeds.

Ishibashi et al. (2012) have concluded that the repression of GAMyb mRNA was released by $\mathrm{H}_{2} \mathrm{O}_{2}$ via PKABA and this $\mathrm{H}_{2} \mathrm{O}_{2}$ subsequently promoted the production of $\alpha$-amylase mRNA, thereby suggesting that $\mathrm{GA}$ generated $\mathrm{H}_{2} \mathrm{O}_{2}$, act as a signal that antagonizes ABA signaling in aleurone cells.

Ethylene is another hormone that acts as a positive regulator of seed germination. In soybean seeds, Ishibashi et al. (2013) observed that during seed imbibition ROS are produced, which further promotes ethylene production in sunflower seeds. Recently, Arc et al. (2013) have reported that the interaction between $\mathrm{ABA}$ and ethylene have antagonistic effects during seed germination. Moreover, by giving special consideration to crosstalk between ABA, ethylene, and ROS, mechanisms of action of ROS in the process of germination have been elucidated (Figure 3).

According to Barba-Espín et al. (2011) ROS also participate in breaking seed dormancy and in germination by activating the oxidative pentose phosphate pathway (oxPPP). The authors observed that the exogenous application of $\mathrm{H}_{2} \mathrm{O}_{2}$ induces the carbonylation of enzymes taking part in restoration of reducing power during glycolysis, which stimulated oxPPP. Moreover, a relationship between $\mathrm{H}_{2} \mathrm{O}_{2}$ contents and gene expression related to MAPKs has also been noticed by Barba-Espín et al. (2011). According to $\mathrm{Xu}$ et al. (2010) during seed germination, MAPK cascades affect cell division and the hormone so, Barba-Espín et al. (2011) pointed out that variations in $\mathrm{H}_{2} \mathrm{O}_{2}$ contents (increases during germination) of seed may induce germination thereby activating those MAPK cascades.

\section{ROS and Root Gravitropism}

After seed germination, the part of seedling which have to make root and shoot, sense the direction of the gravity vector and elicit gravitropic growth, generally sending the roots to downward and shoot to return to upward and directed growth. Generally it is accepted that growth responses reveal differential auxin redistribution to the flanks of the organ that results into reduction of elongation on one side and acceleration on the other. This differential growth in response to gravity leads to the bending of organ. These gravitropism responses have been connected to ROS generation in the roots of Arabidopsis and maize (Joo et al., 2001, 2005). In gravistimulated roots, ROS accumulation was found asymmetrical to the lower cortex within $30 \mathrm{~min}$ of reorientation, which becomes symmetrical upon longer stimulation (Joo et al., 2001). Asymmetrical application of $\mathrm{H}_{2} \mathrm{O}_{2}$ impregnated agar block causes root bending toward block. Here, some caution must be exercised such as $\mathrm{H}_{2} \mathrm{O}_{2}$ application will also interact with the wall that might have profound effect on cell extensibility. ROS are well-known to play a critical role in cell integrity that might also potentially lead to growth arrest. However, treatment with $N$-acetyl cysteine (NAC)like ROS scavengers was observed to inhibit the response or curvature without affecting growth rate thereby suggesting that asymmetrical ROS generation is responsible for the gravitropic response (Joo et al., 2001). As the gravitropic responses are known to originate from inhibition of root elongation on the lower flank of the root, these findings are reliable with ROS accumulation to the lower flank acting as a growth inhibitor. 
It was thought that auxin might be a primary regulator of such kind of root elongation where it is accumulated on the lower flank to inhibit the growth of gravistimulated root. Consistent with these thoughts, Schopfer et al. (2002) reported that auxin can evoke ROS generation in a process which shows a close parallels to the animal model of ROS generation via NAPDH oxidases (Joo et al., 2005). A similar story is also emerging of a potential role of ROS in the gravitropic response of the maize roots. The role of ROS in auxin-induced root gravitropic responses has been reported in Zea mays (Joo et al., 2001), and results strongly suggest that ROS-mediated auxin redistribution by gravity stimulates an increase in gravitropic curving. Firstly, Joo et al. (2001) noticed that ROS are formed subsequent to gravitropic stimulus. When maize roots were kept horizontally, the ROS generation was detected in the apex, stimulating the gravitropic response (Joo et al., 2001). Secondly, ROS production is increased by auxin application to root cells in intact plants as well as in root protoplast cultures (Cervantes, 2001). Further treatment of roots with $N$-1-naphthylphthalamic acid (NPA, an auxin transport inhibitor) results in inhibition of gravitropism and the effect of NPA can be reversed by adding $\mathrm{H}_{2} \mathrm{O}_{2}$ which has indicated a direct causal relationship between auxin, ROS, and gravitropism (Cervantes, 2001). It has been observed that root bending, after pretreatment with the auxin transport inhibitor NPA, was brought about by unilateral ROS application to vertical roots. However, ROS scavenging by the antioxidants NAC, trolox and ASA inhibits root gravitropism (Joo et al., 2001). However, the effect of NPA was reversed by addition of $\mathrm{H}_{2} \mathrm{O}_{2}$. Joo et al. (2001) pointed out that ROS might work by kinase activation, but also considered that other mediators of the gravitropic response, such as inositol $(1,4,5)$ trisphosphate and calcium, might be involved. Furthermore, Joo et al. (2005) observed that phosphatidylinositol 3-kinase is involved in auxin-mediated ROS production that regulates root gravitropism while retreatment with the phosphatidylinositol 3kinase activity inhibitor LY294002 blocked the auxin- mediated ROS generation, decreasing the sensitivity of root tissue to gravistimulation (Joo et al., 2005).

It is well-known that in plant gravitropism, redistribution of auxin plays an important role (Petrasek and Friml, 2009) in ROS mediated root gravitropism. To find out the role of auxin and ROS, Lupini et al. (2013) used the auxin transport inhibitors 2,3,5-triiodobenzoic acid (TIBA) and naphthylphthalamic acid (NPA) and a secondary metabolite coumarin which are known to alter the gravitropic responses in the roots of $A$. thaliana. Coumarin itself did not show any change in gravitropic response, but when added with NPA or TIBA, it reversed the effect of inhibitors (Lupini et al., 2013). Moreover, Lupini et al. (2013) studied ROS distribution in root tips and reported that NPA or TIBA causes distribution of $\mathrm{O}_{2}^{-}$around the root tip, which disappeared after coumarin addition to both treatments, restoring ROS localized distribution. These findings suggest that coumarin effect in restoring the root curvature did not depend upon auxin redistribution, but was mediated by ROS generation. Further to investigate the localization of ROS, Libik-Konieczny et al. (2015) by using blue formazan (NBT; precipitates $\mathrm{O}_{2}^{\bullet}-$ accumulation) and 3,3'-diaminobenzidine
(DAB; for $\mathrm{H}_{2} \mathrm{O}_{2}$ accumulation) demonstrated that $\mathrm{O}_{2}^{\bullet-}$ was localized within the tip of root primordia, vascular cylinder cells as well as in the distal and middle parts of newly formed organs during the early stages of rhizogenesis; while $\mathrm{H}_{2} \mathrm{O}_{2}$ was pronounced in cortical and vascular bundle cells. On adding DPI to the medium, $\mathrm{O}_{2}^{\bullet}-$ accumulation was then restricted to epidermis cells, while that of $\mathrm{H}_{2} \mathrm{O}_{2}$ was limited in vascular tissues (Libik-Konieczny et al., 2015). These findings suggest that $\mathrm{O}_{2}^{\bullet}$ - engages itself in the process of rhizogenesis, while $\mathrm{H}_{2} \mathrm{O}_{2}$ is engaged in developmental processes such as cell growth.

\section{ROS in Growth and Development of Root Hair and Pollen Tube}

In plant system, the tip growth in either of the cases is mainly associated with the deposition of membrane and new wall materials centered toward the apex of elongating cells, thereby resulting into the formation of tube-like structure. To produce a correct shape and size, cell expansion needs to be carefully regulated. Polar cell growth is continued by oscillatory feedback loops including three main components, i.e., ROS, $\mathrm{Ca}^{2+}$ and $\mathrm{pH}$ that together play an important role in regulating this process over time (Mangano et al., 2016). Apoplastic ROS balance controlled by NADPH oxidases and class III peroxidases has a great impact on cell wall properties during cell expansion (Mangano et al., 2016).

During expansion of polar cell (root or pollen), the apical zone is characterized by a tip-focused elevated cytoplasmic $\mathrm{Ca}^{2+}$ $\left({ }_{c y t} \mathrm{Ca}^{2+}\right)$ gradient and related proteins along with the apoplastic ROS (apo ROS) generation (Konrad et al., 2011; Qin and Yang, 2011; Hepler et al., 2012; Steinhorst and Kudla, 2013). Cell takes $\mathrm{Ca}^{2+}$ either from external sources or stored in the cell wall and this $\mathrm{Ca}^{2+}$ released by changing apopH which is mainly controlled by plasma membrane located activation/deactivation of $\mathrm{H}^{+}$pumps (AHA). Additionally, $\mathrm{Ca}^{2+}$ can be stored in vacuoles and ER-Golgi and released into the cytosol. To maintain low concentrations of ${ }_{\text {cyt }} \mathrm{Ca}^{2+}$, autoinhibitory P-type IIB $\mathrm{Ca}^{2+}$ ATPases (ACAs) transport $\mathrm{Ca}^{2+}$ back to the apoplast. In addition to this, the $\mathrm{H}^{+} / \mathrm{Ca}^{2+}$ antiporter activity of calciumexchanger (CAX) translocates $\mathrm{Ca}^{2+}$ back to the apoplast and, at the same time, imports $\mathrm{H}^{+}$into the cytoplasm. In the tip zone, high levels/concentration of ${ }_{c y t} \mathrm{Ca}^{2+}$ activates apo ROS generation by NADPH oxidases (NOXs). Moreover, high levels of ROS quickly elevate the concentration of ${ }_{\mathrm{cyt}} \mathrm{Ca}^{2+}$ (Foreman et al., 2003; Duan et al., 2014) by an unknown phenomenon. NOXH/NOXJ (Wu et al., 2010; Boisson-Dernier et al., 2013) and NOXC (Foreman et al., 2003; Monshausen et al., 2007, 2008) were previously proposed to connect apo ROS production with the rapid activation of $\mathrm{Ca}^{2+}$ channels (CaCs) of plasma membrane in growing pollen tubes and root hairs, respectively. The idea that ROS are important for sustaining polar growth came into existence with the cloning of root hair defective 2 (rhd2) mutants of $A$. thaliana (Foreman et al., 2003). In rhd2 mutant background, according to Monshausen et al. (2007) and Macpherson et al. (2008) root hairs correctly initiated their developmental program and form bulges on the epidermal cell side but they fail to elongate/transition to tip growth. 
When alleles of the rhd2 were cloned, they were found to inhabiting a gene encoding the respiratory burst oxidase homolog C (AtRBOHC) of Arabidopsis, an NADPH oxidase similar to mammalian gp91phox (The phox91 family is conserved throughout the animal, plant and, fungal kingdoms; Foreman et al., 2003), responsible for ROS production during oxidative burst. It means that RHD2 plays an important role in electron transfer from NADPH to an electron acceptor, and resulting in ROS formation. Besides RHD2, another target of ROS signaling in growing root hair has been reported, i.e., OXIDATIVE BURST INDUCIBLE1 (OXI1) kinase (Rentel and Knight, 2004). OXI1 is a Ser-Thr kinase, which plays a role in elongation of root hairs, as it is slightly shorter in oxil mutant than wild type. It was suggested that RHD2-mediated ROS leads to the activation of a MAPKs cascade through OXI1 during growth of root hairs.

A ROS burst is crucial for the rupturation of pollen tube and sperm release (Duan et al., 2014). Oscillatory growth is also related to changes in $\mathrm{pH}$ which is regulated by cation $\left(\mathrm{H}^{+}\right)$/anion $\left(\mathrm{OH}^{-}\right)$-permeable channels, by membrane $\mathrm{H}^{+}$ATPases (AHA; Falhof et al., 2016) and antiporters $\left(\mathrm{Ca}^{2+} / \mathrm{H}^{+}\right.$ exchangers). AHA is supposed to be responsible for pumping $\mathrm{H}^{+}$out of pollen tubes remains to be identified while AHA2 is highly expressed in growing root hairs. AHA directly controls apoplastic $\mathrm{pH}\left({ }_{\text {apo }} \mathrm{pH}\right)$, which affects the enzymatic mechanism that alters cell wall components during cell expansion. Polar growth entails the stretching and deformation of the existing wall in the apical zone, which is escorted by the secretion of new wall materials (Altartouri and Geitmann, 2015). Oscillations in $\mathrm{Ca}^{2+}$, ROS and $\mathrm{pH}$ are coupled to transient cell wall loosening to facilitate turgor-driven localized cell expansion (Braidwood et al., 2014; Spartz et al., 2014; Wolf and Höfte, 2014). In cells, growth is determined by the balance between cell wall loosening and stiffening. Root hair growth has to occur not only in accordance with the loosening of the cell wall to allow the expansion at its tip, but also with a need to avoid tip bursting by maintenance of wall integrity. In order to attain this pattern, the factors engaged in pollen tube growth such as ${ }_{\text {cyt }} \mathrm{Ca}^{2+}$ levels, $\mathrm{pH}$, and NADPH are found to oscillate in such a manner in which the highest concentration follows the highest peak in growth, in concert to maintain the periodic oscillations (Cárdenas et al., 2006; Lovy-Wheeler et al., 2006). In root hairs, the maximum of these oscillatory fluctuations in apo ROS concentration and apoplastic/cytoplasmic $\mathrm{pH}$ lead cell growth peaks by 7-8 s, while ${ }_{\text {cyt }} \mathrm{Ca}^{2+}$ oscillations delay oscillations in cell growth by approximately 5-6 s (Monshausen et al., 2007, 2008). In pollen tubes, the oscillations in ${ }_{\mathrm{cyt}} \mathrm{Ca}^{2+}$ concentration are lagged by approximately $11 \mathrm{~s}$ in relation to cell expansion rates (Pierson et al., 1994). Thus, polar cell growth is improved, and perhaps rapidly repressed, by high concentration of $\mathrm{cyt}^{\mathrm{Ca}^{2+}}$ and, consequently, high apo ROS concentrations and a more alkaline apo $\mathrm{pH}$.

In Arabidopsis, by using high-resolution growth measurements, Monshausen et al. (2008) showed that the frequency of growth pulses was approximately 3 per minute, similar to the frequency of pulses of ROS production and to the oscillations in the apical $\mathrm{Ca}^{2+}$ gradient. A comprehensive study of these oscillations implied a growth burst at $5 \mathrm{~s}$ due to an increase in tipfocused $\mathrm{Ca}^{2+}$ that may be mediated by a stretch-activated $\mathrm{Ca}^{2+}$ channel, which is followed $2 \mathrm{~s}$ later by ROS production in the wall (Monshausen et al., 2008). According to Monshausen and Gilroy (2009), this ROS production may play a role in covalent cross linking of polymers, and therefore strengthen the wall to prevent expansion and bursting. Monshausen et al. (2007) reported that tip growth ceased after the addition of external $\mathrm{H}_{2} \mathrm{O}_{2}$; however, scavenging of ROS promoted tip bursting, which suggests that ROS also play a role in wall rigidification. From these facts, it can be concluded that ROS-activated $\mathrm{Ca}^{2+}$-permeable channels induce $\mathrm{Ca}^{2+}$ influx to increase the ${ }_{\mathrm{cyt}} \mathrm{Ca}^{2+}$ after the beginning of Rboh-mediated ROS generation, which further activates Rbohs. Therefore, $\mathrm{Ca}^{2+}$ increases in the cytoplasm probably response to increase ROS that alter $\mathrm{Ca}^{2+}$ influx.

If we are talking about ROS signaling, it is noteworthy that changes in extracellular $\mathrm{pH}$ correlate with the oscillations in growth, which permit the alteration of tip growth in root hairs of Arabidopsis (Monshausen et al., 2007). The stiffening of the cell wall is carried out by both ROS and increased $\mathrm{pH}$, which make cell wall resistant to turgor pressure. In the growing tip, oscillation of $\mathrm{Ca}^{2+}$ gradients is followed by alkalinization peaks in the apoplast along with the constitutive $\mathrm{O}_{2}^{\bullet}-$ generation across the subapical part of the tip (Monshausen et al., 2009; Swanson and Gilroy, 2010). An oscillatory component of extracellular $\mathrm{pH}$ at the tip of pollen tubes has been reported by Messerli and Robinson (2007), that changes the phase by producing ROS and increases the growth by increasing the $\mathrm{Ca}^{2+}$ accumulation (Messerli and Robinson, 2007). A similar series of events ROS, $\mathrm{pH}, \mathrm{Ca}^{2+}$, and growth have also been reported in root hair tips (Monshausen et al., 2007). These findings put forward that one factor (either ROS or wall $\mathrm{pH}$ ) compensate with at wall dynamics as well as in controlling the cytosolic activities needed to maintain the growth (Figure 4).

Lateral root development is controlled by the antagonistic action of auxin and ABA. Auxin promotes the separation of pericycle initials and cell expansion while, ABA is essential during each stage of lateral root growth as it regulates the balance between cell proliferation and differentiation in the root meristem and in lateral root primordia (Dubrovsky et al., 2008; De Rybel et al., 2010; Lavenus et al., 2013). Both hormones also mediate ROS accumulation in growing roots and promote cell expansion. A transcriptomic analysis (Manzano et al., 2014) of roots treated with auxin revealed that majority of the peroxidase genes in the cs-SKP2B (SKP2B is a marker for lateral root development while cs-SKP2B dataset is its specific expression pattern of cell sorting that regulates the developmental program endogenously) dataset are not regulated by ABA. Tsukagoshi et al. (2010) proposed that for growth regulation at root meristem, Prxs activity (regulated by UPB1) acts independently of the auxin pathway. In contrast, Ma et al. (2014) advocated that the auxin response involves ROS signaling. Peroxidases take part in lignin formation in the primary cell wall (Marjamaa et al., 2009). It is notable that indole-3 acetic acid (IAA) is easily degraded by plant Prxs (Cosio et al., 2008), which leads to the reduction of auxin pools. In tobacco plant, free IAA 


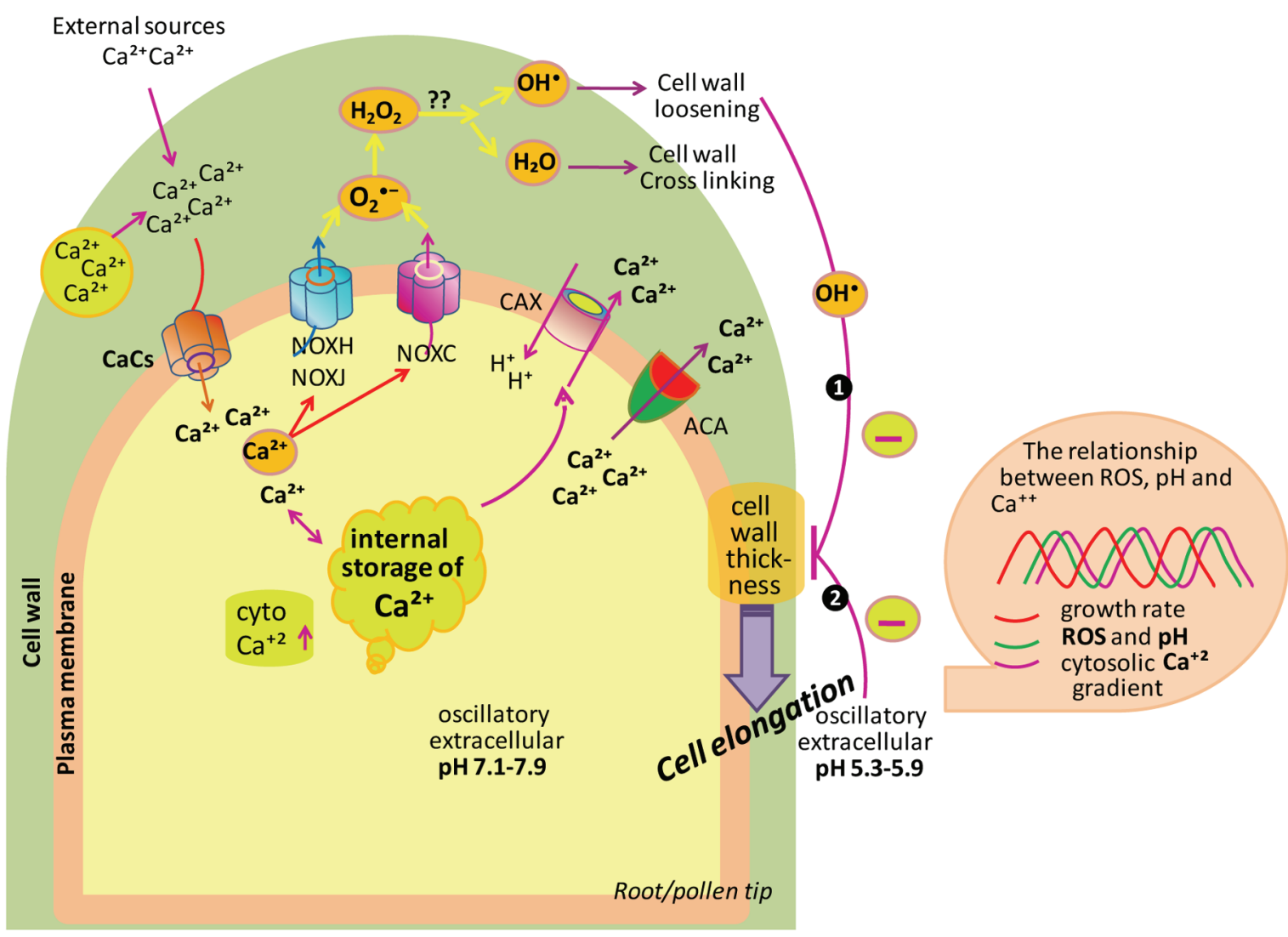

FIGURE 4 | Model depicting the role of ROS, $\mathrm{Ca}^{2+}$ and pH in tip growth of root/pollen cells. Cell uptakes $\mathrm{Ca}^{2+}$ from its surrounding. To maintain the low levels of $\mathrm{cyt}^{\mathrm{Ca}}{ }^{2+}$, ACAs transport $\mathrm{Ca}^{2+}$ back to the apoplast. Besides this, the $\mathrm{H}^{+} / \mathrm{Ca}^{2+}$ antiporter translocates $\mathrm{Ca}^{2+}$ back to the apoplast and, at the same time, imports $\mathrm{H}^{+}$into the cytoplasm. The $\mathrm{cyt}_{\mathrm{Ca}} \mathrm{Ca}^{2+}$ activates $\mathrm{NOXC}$ and $\mathrm{NOXH} / \mathrm{NOXJ}$ to produce ${ }_{\text {apo }} \mathrm{ROS}$ in root hairs and pollen tubes, respectively. NOX produces apoplastic $\mathrm{O}_{2}^{\bullet}$-, which is dismutated by SOD to $\mathrm{H}_{2} \mathrm{O}_{2}$. Also, apo $\mathrm{H}_{2} \mathrm{O}_{2}$ and $\mathrm{O}_{2}$ generate $\mathrm{OH}$ (in the hydroxylic cycle) which catalyzes the nonenzymatic cleavage of polysaccharides, thereby allowing tip growth. Box on right side showing that extracellular ROS, $\mathrm{pH}$ as well as $\mathrm{cyt}_{\mathrm{Ca}}{ }^{2+}$ are coupled to growth oscillations. (Modified after Monshausen et al., 2009; Mangano et al., 2016).

levels decreased in roots, indicating that alteration of auxin level is critical for the inhibition of lateral root formation in plants (Moriwaki et al., 2011). Recently, it was proposed that root architecture is determined by the redox-mediated GPX family (Passaia et al., 2014). Moreover, Passaia et al. (2014), through genetic analysis, showed that $g p x$ mutants differentially affect lateral root formation (except $g p \times 3-2$ mutants), with all $g p x$ mutants showing expanded lateral root primordia (LRP). Passaia et al. (2014) have also observed that GPX1 and GPX7 are the two main Prxs to play a significant role in the regulation of lateral root development and root architecture, which is also associated with auxin-dependent control of lateral root formation. In addition, Manzano et al. (2014) have shown that $\mathrm{H}_{2} \mathrm{O}_{2}$ and $\mathrm{O}_{2}^{\bullet}-$ actively participate in lateral root development. They have also reported that in the cs-SKP2B dataset, several enzymes are involved in ROS formation, including AtrbohC, cytochrome P450 electron carrier proteins, and lipoxygenases. These findings suggested that ROS signaling is an important part of lateral root development. It can be summarized that Prxs activities (regulated by UPB1) regulate emergence of lateral roots via ROS signaling, most probably by promoting transition from cellular proliferation to differentiation (as discussed in previous section; Figure 2).

\section{ROS and Leaf Growth and Development}

The complex coordination between cell proliferation and cell expansion decides the final size of a single organ or organism (Lu et al., 2014). Plant leaves are initiated by the proliferation of meristematic cells and then by cell expansion without additional division in a second phase (Beemster et al., 2005). An equilibrium between negative and positive regulators controls both phases by a large number of genetic pathways. For instance, TFs play a vital role (Townsley and Sinha, 2012). Of course, cell expansion is affected by changes in cell wall architecture and content (Bringmann et al., 2012; Rubio-Diaz et al., 2012). Such alterations may be due to Prxs that alter ROS levels in leaves (Passardi et al., 2004).

The Prxs particularly apoplastic, directly control stiffness of the cell wall, either by promoting or by restricting cellular extension (Tsukagoshi et al., 2010; Lee et al., 2013). In the first scenario, $\mathrm{O}_{2}^{\bullet}-$ generated by cell wall peroxidases, promote 
expansion by cleaving the cell wall polysaccharides and act as cell wall loosening agents (Müller et al., 2009). In contrast, $\mathrm{H}_{2} \mathrm{O}_{2}$ production in the cell wall promotes rigid cross-linking of cell wall components and results in growth restriction or making the cell wall stiffer (Passardi et al., 2004; Lu et al., 2014). The activity and expression of Prxs are suppressed by KUODA1 (KUA1), a MYB-like TF that was found to function as a positive regulator of cell expansion during leaf development by altering apoplastic ROS homeostasis in A. thaliana (Lu et al., 2014). The overexpression of KUA1 results in increased cell size with larger leaves without affecting the cell number (Lu et al., 2014). In contrast, the kua1-1mutant has smaller leaves than the wild type due to a decrease in cell size, while the cell number was again unaffected. Moreover, the kual mutant shows elevated levels of $\mathrm{H}_{2} \mathrm{O}_{2}$ and increased activity of class III Prxs. The disturbance of KUA1 causes an increase in Prxs activity and results in smaller leaf cells. Therefore, expansion of the cell as well as the final size of the organ is controlled by ROS homeostasis as modulated by KUA1 (Lu et al., 2014). This positive regulation/promotion can be interlinked with change in apoplastic $\mathrm{H}_{2} \mathrm{O}_{2}$ levels and it is noteworthy that changes in $\mathrm{H}_{2} \mathrm{O}_{2}$ level can also affect the $\mathrm{O}_{2}^{\bullet}-$ pool (Liszkay et al., 2003). Of note, in the case of KUA1, $\mathrm{H}_{2} \mathrm{O}_{2}$ mediated inhibitory effect of Prxs, seems to be the fundamental link for the regulation of leaf cell expansion. The equilibrium between $\mathrm{O}_{2}^{\bullet}-$ and $\mathrm{H}_{2} \mathrm{O}_{2}$ regulates cell proliferation and differentiation zones that decide the size of an organ (as discussed in previous section). Lu et al. (2014) showed that suppression of Prxs expression by KUA1 increased leaf cell expansion, without causing the increase in leaf cell proliferation. Moreover, the size of the first cortical root cell was decreased by $\mathrm{H}_{2} \mathrm{O}_{2}$ treatments (Tsukagoshi et al., 2010), the root-localized Prxs are most probably essential to uphold low $\mathrm{H}_{2} \mathrm{O}_{2}$ levels to support root cell expansion. Contrary to this, Lu et al. (2014) also reported that inhibition of Prxs activity improves leaf size thereby suggesting that apoplastic Prxs mainly produce $\mathrm{H}_{2} \mathrm{O}_{2}$ that leads to cell wall crosslinking in leaves (Passardi et al., 2004). Therefore, the impact of Prxs specifically their effect on the $\mathrm{H}_{2} \mathrm{O}_{2}$ level seems to comprise greater opposing effects on leaf growth in plants.

\section{CONCLUSION AND FUTURE DIRECTIVES}

In spite of amazing development in our understanding of ROS biology, the exact nature of the ROS-signaling network largely remains mysterious. The present review is an attempt to adress the regulatory action of ROS in plant growth and development. Earlier these were considered to be toxic by-products only, but now they have been found to function as central players in complex signaling networks. We have tried here to uncover the beneficial role of ROS as signaling molecules. Undoubtedly, in the past decade, our understanding in the field of ROS signaling have significantly improved but miles we have to go. We are entering in an exciting era of ROS signaling in plants. Our stage is set and it's time to fit the different parts of the puzzle into its right place. Definitely, by uncovering novel biological roles of ROS, our understanding in the field of ROS signaling have become more than superficial, but many questions remain to be answered.

- For instance, is it possible to transport ROS from one subcellular site to another, and if possible, how do ROS signals journey within or across different cells?

- How are ROS-modulated gene networks linked with other signaling networks?

- Are they affected by changes in membrane potential?

- How does the effectiveness of ROS signals differ among subcellular compartments? How do NADPH oxidases participate in generating these signals?

- What are the concentrations of ROS in different sub-cellular compartments?

- Does each source contribute equally to the cellular ROS pool? Are specific ROS signatures induced by different stimuli?

- How do plant cells sense ROS?

- What are threshold levels of ROS at which they function as signaling molecules?

Answers to these questions are crucial for elucidating mechanisms of ROS signaling. Our current understating regarding the involvement of ROS in developmental processes largely depends on some discovered components of signaling pathways such as NOXs, OXI1, $\mathrm{Ca}^{2+}$ influx and efflux, and some TFs. Further studies are needed to properly explain the complex regulatory machinery that integrates ROS signals with components of signaling pathways for the regulation of growth and development of plants. ROS are associated with many biotic and abiotic responses, and interpreting ROS signaling is expected to have a noteworthy impact on biotechnology and agriculture, possibly leading to crop development by enhancing yield under suboptimal conditions. Future work will no doubt reveal novel signaling roles for ROS and their interaction with other signals, and hence future of ROS research is very promising.

\section{AUTHOR CONTRIBUTIONS}

VS and SP have conceptualized the review article. RS, SS, PP, RM, DT, VS, DC, and SP are being involved in writing this review article. RS and SS equally contributed in this review article.

\section{ACKNOWLEDGMENTS}

The University Grants Commission, New Delhi, is acknowledged for providing financial support to RS, PP, and SS in the form of D.Phil. research scholarship and RM in the form of Dr. D. S. Kothari Post Doc. fellowship to carry out this work. 


\section{REFERENCES}

Adachi, H., Nakano, T., Miyagawa, N., Ishihama, N., Yoshioka, M., Katou, Y., et al. (2015). WRKY transcription factors phosphorylated by MAPK regulate a plant immune NADPH oxidase in Nicotiana benthamiana. Plant Cell 27, 2645-2663. doi: 10.1105/tpc.15.00213

Aguirre, J., Rios-Momberg, M., Hewitt, D., and Hansberg, W. (2005). Reactive oxygen species and development in microbial eukaryotes. Trends Microbiol. 13, 111-118. doi: 10.1016/j.tim.2005.01.007

Aken, V., and Van Breusegem, F. (2015). Licensed to kill: mitochondria, chloroplasts, and cell death Olivier. Trends Plant Sci. 20, 754-766. doi: 10.1016/j.tplants.2015.08.002

Altartouri, B., and Geitmann, A. (2015). Understanding plant cell morphogenesis requires real-time monitoring of cell wall polymers. Curr. Opin. Plant Biol. 23, 76-82. doi: 10.1016/j.pbi.2014.11.007

Ambastha, A. K., Gong, T., Bolan, S., Dinh, T. A., and Lim, T. C. (2015). "Automated prognosis analysis for traumatic brain injury CT images," in Proceeding of the 3rd Asian Conference on Pattern Recognition (ACPR), Beijing.

Amien, S., Kliwer, I., Márton, M. L., Debener, T., Geiger, D., Becker, D., et al. (2010). Defensin-like ZmES4 mediates pollen tube burst in maize via opening of the potassium channel KZM1. PLOS Biol. 8:e1000388. doi: 10.1371/journal.pbio. 1000388

Apel, K., and Hirt, H. (2004). Reactive oxygen species: metabolism, oxidative stress, and signal transduction. Annu. Rev. Plant Biol. 55, 373-399. doi: 10.1146/annurev.arplant.55.031903.141701

Arc, E., Sechet, J., Corbineau, F., Rajjou, L., and Marion-Poll, A. (2013). ABA crosstalk with ethylene and nitric oxide in seed dormancy and germination. Front. Plant Sci. 4:63. doi: 10.3389/fpls.2013.00063

Asada, K. (2006). Production and scavenging of reactive oxygen species in chloroplasts and their functions. Plant Physiol. 141, 391-396. doi: 10.1104/pp.106.082040

Ashtamker, C., Kiss, V., Sagi, M., Davydov, O., and Fluhr, R. (2007). Diverse subcellular locations of cryptogein-induced reactive oxygen species production in tobacco bright yellow-2 cells. Plant Physiol. 143, 1817-1826. doi: 10.1104/pp.106.090902

Bahin, E., Bailly, C., Sotta, B., Kranner, I., Corbineau, F., and Leymarie, J. (2011). Crosstalk between reactive oxygen species and hormonal signaling pathways regulates grain dormancy in barley. Plant Cell Environ. 34, 980-993. doi: 10.1111/j.1365-3040.2011.02298.x

Bailly, C. (2004). Active oxygen species and antioxidants in seed biology. Seed Sci. Res. 14, 93-107. doi: 10.1079/SSR2004159

Bailly, C., El-Maarouf-Bouteau, H., and Corbineau, F. (2008). From intracellular signaling networks to cell death: the dual role of reactive oxygen species in seed physiology. C. R. Biol. 331, 806-814. doi: 10.1016/j.crvi.2008. 07.022

Banfi, B., Tirone, F., Durussel, I., Knisz, J., Moskwa, P., Molnar, G. Z., et al. (2004). Mechanism of $\mathrm{Ca}^{2+}$ activation of the NADPH oxidase 5 (NOX5). J. Biol. Chem. 279, 18583-18591. doi: 10.1074/jbc.M310268200

Barba-Espín, G., Diaz-Vivancos, P., Job, D., Belghazi, M., Job, C., and Hernandes, J. A. (2011). Understanding the role of $\mathrm{H}_{2} \mathrm{O}_{2}$ during pea seed germination: a combined proteomic and hormone profiling approach. Plant Cell Environ. 34, 1907-1919. doi: 10.1111/j.1365-3040.2011.02386.x

Baxter, A., Mittler, R., and Suzuki, N. (2014). ROS as key players in plant stress signalling. J. Exp. Bot. 65, 1229-1240. doi: 10.1093/jxb/ert375

Bazin, J., Langlade, N., Vincourt, P., Arribat, S., Balzergue, S., El-MaaroufBouteau, H., et al. (2011). Targeted mRNA oxidation regulates sunflower seed dormancy alleviation during dry after-ripening. Plant Cell 23, 2196-2208. doi: 10.1105/tpc.111.086694

Bedard, K., and Krause, K. H. (2007). The Nox family of ROS-generating NADPH oxidases: physiology and pathophysiology. Physiol. Rev. 87, 245-313. doi: 10.1152/physrev.00044.2005

Beemster, G. T. S., Veylder, L. D., Vercruysse, S., West, S., Rombaut, D., Hummelen, P. V., et al. (2005). Genome-wide analysis of gene expression profiles associated with cell cycle transitions in growing organs of Arabidopsis. Plant Physiol. 138, 734-743. doi: 10.1104/pp.104.053884

Bewley, J. D., Bradford, K. J., Hilhorst, H. W. M., and Nonogaki, H. (2013). Seeds: Physiology of Development, Germination and Dormancy. Berlin: Springer.
Bhattacharjee, S. (2012). The language of reactive oxygen species signaling in plants. J. Bot. 2012, 985298. doi: 10.1155/2012/985298

Bhattacharjee, S. (2014). Membrane lipid peroxidation and its conflict of interest: the two faces of oxidative stress. Curr. Sci. 107, 1811-1823.

Bindschedler, L. V., Dewdney, J., Blee, K. A., Stone, J. M., Asai, T., Plotnikov, J., et al. (2006). Peroxidase-dependent apoplastic oxidative burst in Arabidopsis required for pathogen resistance. Plant J. 47, 851-863. doi: 10.1111/j.1365313X.2006.02837.x

Boisson-Dernier, A., Lituiev, D. S., Nestorova, A., Franck, C. M., Thirugnanarajah, S., and Grossniklaus, U. (2013). ANXUR receptor-like kinases coordinate cell wall integrity with growth at the pollen tube tip via NADPH oxidases. PLOS Biol. 11:e1001719. doi: 10.1371/journal.pbio.1001719

Bollhöner, B., Prestele, J., and Tuominen, H. (2012). Xylem cell death: emerging understanding of regulation and function. J. Exp. Bot. 63, 1081-1094. doi: $10.1093 / j x b / e r r 438$

Bosch, M., and Franklin-Tong, N. (2007). Temporal and spatial activation of caspase-like enzymes induced by self-incompatibility in papaver pollen. Proc. Natl. Acad. Sci. U.S.A. 104, 18327-18332. doi: 10.1073/pnas.0705826104

Bosch, M., Poulter, N. S., Perry, R. M., Wilkins, K. A., and Franklin-Tong, V. E. (2010). Characterization of a legumain/vacuolar processing enzyme and YVADase activity in Papaver pollen. Plant Mol. Biol. 74, 381-393. doi: 10.1007/s11103-010-9681-9

Bouche, N., Fait, A., Bouchez, D., Moller, S. G., and Fromm, H. (2003). Mitochondrial succinic-semialdehyde dehydrogenase of the gammaaminobutyrate shunt is required to restrict levels of reactive oxygen intermediates in plants. Proc. Natl. Acad. Sci. U.S.A. 100, 6843-6848. doi: 10.1073/pnas. 1037532100

Braidwood, L., Breuer, C., and Sugimoto, K. (2014). My body is a cage: mechanisms and modulation of plant cell growth. New Phytol. 201, 388-402. doi: $10.1111 / \mathrm{nph} .12473$

Bringmann, M., Li, E., Sampathkumar, A., Kocabek, T., Hauser, M. T., and Persson, S. (2012). POM-POM2/cellulose synthase interacting 1 is essential for the functional association of cellulose synthase and microtubules in Arabidopsis. Plant Cell 24, 163-177. doi: 10.1105/tpc.111.093575

Cai, S., and Lashbrook, C. C. (2008). Stamen abscission zone transcriptome profiling reveals new candidates for abscission control: enhanced retention of floral organs in transgenic plants overexpressing Arabidopsis ZINC FINGER PROTEIN2. Plant Physiol. 146, 1305-1321. doi: 10.1104/pp.107.110908

Caliskan, M., and Cuming, A. C. (1998). Spatial specificity of $\mathrm{H}_{2} \mathrm{O}_{2}$-generating oxalate oxidase gene expression during wheat embryo germination. Plant J. 15, 165-171. doi: 10.1046/j.1365-313X.1998.00191.x

Cárdenas, L., McKenna, S. T., Kunkel, J. G., and Hepler, P. K. (2006). NAD(P)H oscillates in pollen tubes and is correlated with tip growth. Plant Physiol. 142, 1460-1468. doi: 10.1104/pp.106.087882

Carmody, M., Crisp, P. A., d’Alessandro, S., Ganguly, D., Gordon, M., Havaux, M., et al. (2016). Uncoupling high light responses from singlet oxygen retrograde signaling and spatial-temporal systemic acquired acclimation in Arabidopsis. Plant Physiol. 171, 1734-1749. doi: 10.1104/pp.16.00404

Cervantes, E. (2001). ROS in root gravitropism: the auxin messengers? Trends Plant Sci. 6, 556. doi: 10.1016/S1360-1385(01)02197-5

Chen, H. J., Wu, S. D., Huang, G. J., Shen, C. Y., Afiyanti, M., Li, W. J., et al. (2012). Expression of a cloned sweet potato catalase SPCAT1 alleviates ethephon mediated leaf senescence and $\mathrm{H}_{2} \mathrm{O}_{2}$ elevation. J. Plant Pysiol. 169, 86-97. doi: 10.1016/j.jplph.2011.08.002

Chen, S. P., Lin, I. W., Chen, X., Huang, Y. H., Chang, H. C., Lo, H. S., et al. (2016). Sweet potato NAC transcription factor, IbNAC1, upregulates sporamin gene expression by binding the SWRE motif against mechanical wounding and herbivore attack. Plant J. 86, 234-248. doi: 10.1111/tpj.13171

Choi, H. W., Kim, Y. J., Lee, S. C., Hong, J. K., and Hwang, B. K. (2007). Hydrogen peroxide generation by the pepper extracellular peroxidase $\mathrm{CaPO} 2$ activates local and systemic cell death and defense response to bacterial pathogens. Plant Physiol. 145, 890-904. doi: 10.1104/pp.107.103325

Choi, W. G., Hilleary, R., Swanson, S. J., Kim, S. H., and Gilroy, S. (2016). Rapid, long distance electrical and calcium signaling in plants. Annu. Rev. Plant Biol. 67, 287-307. doi: 10.1146/annurev-arplant-043015-112130

Chopra, K. R. (2012). Leaf senescence and abiotic stresses share reactive oxygen species-mediated chloroplast degradation. Protoplasma 249, 469-481. doi: 10.1007/s00709-011-0308-z 
Corbineau, F., Xia, Q., Bailly, C., and El-Maarouf-Bouteau, H. (2014). Ethylene, a key factor in the regulation of seed dormancy. Front. Plant Sci. 5:539. doi: 10.3389/fpls.2014.00539

Cosio, C., Vuillemin, L., De Meyer, M., Kevers, C., Penel, C., and Dunand, C. (2008). An anionic class III peroxidase from zucchini may regulate hypocotyl elongation thanks to its auxin oxidase activity. Planta 229, 823-836. doi: 10.1007/s00425-008-0876-0

Crescenzi, V., Belardinelli, M., and Rinaldi, C. (1997). Polysaccharides depolymerization via hydroxyl radicals attack in dilute aqueous solution. J. Carbo. Chem. 16, 561-572. doi: 10.1080/07328309708007335

de Pinto, M. C., Locato, V., and De Gara, L. (2012). Redox regulation in plant programmed cell death. Plant Cell Environ. 35, 234-244. doi: 10.1111/j.13653040.2011.02387.x

De Rybel, B., Vassileva, V., Parizot, B., Demeulenaere, M., Grunewald, W., Audenaert, D., et al. (2010). A novel aux/IAA28 signaling cascade activates GATA23-dependent specification of lateral root founder cell identity. Curr. Biol. 20, 1697-1706. doi: 10.1016/j.cub.2010.09.007

del Rio, L. A., Sandalio, L. M., Corpas, F. J., and Barroso, J. B. (2006). Reactive oxygen species and reactive nitrogen species in peroxisomes. Production, scavenging, and role in cell signaling. Plant Physiol. 141, 330-335.

Desikan, R., Reynolds, A., Hancock, J. T., and Neill, S. J. (1998). Harpin and hydrogen peroxide both initiate programmed cell death but have differential effects on defence gene expression in Arabidopsis suspension cultures. Biochem. J. 330, 115-120. doi: 10.1042/bj3300115

Diaz-Vivancos, P., Barba-Espin, G., and Hernandez, J. A. (2013). Elucidating hormonal/ROS networks during seed germination: insights and perspectives. Plant Cell Rep. 32, 1491-1502. doi: 10.1007/s00299-013-1473-7

Dietz, K. J. (2016). Thiol-based peroxidases and ascorbate peroxidases: why plants rely on multiple peroxidase systems in the photosynthesizing chloroplast? $\mathrm{Mol}$. Cells 39, 20-25. doi: 10.14348/molcells.2016.2324

Drose, S., and Brandt, U. (2012). Molecular mechanisms of superoxide production by the mitochondrial respiratory chain. Adv. Exp. Med. Biol. 748, 145-169. doi: 10.1007/978-1-4614-3573-0_6

Duan, Q., Kita, D., Johnson, E. A., Aggarwal, M., Gates, L., Wu, H. M., et al. (2014). Reactive oxygen species mediate pollen tube rupture to release sperm for fertilization in Arabidopsis. Nat. Commun. 5, 3129. doi: 10.1038/ncomms4129

Duan, Q., Kita, D., Li, C., Cheung, A. Y., and Wu, H. M. (2010). FERONIA receptor-like kinase regulates RHO GTPase signaling of root hair development. Proc. Natl. Acad. Sci. U.S.A. 107, 17821-17826. doi: 10.1073/pnas.1005366107

Dubrovsky, J. G., Sauer, M., Napsucialy-Mendivil, S., Ivanchenko, M. G., Friml, J., Shishkova, S., et al. (2008). Auxin acts as a local morphogenetic trigger to specify lateral root founder cells. Proc. Natl. Acad. Sci. U.S.A. 105, 8790-8794. doi: 10.1073/pnas.0712307105

Dunand, C., Crevecoeur, M., and Penel, C. (2007). Distribution of superoxide and hydrogen peroxide in Arabidopsis root and their influence on root development: possible interaction with peroxidases. New Phytol.174, 332-341. doi: 10.1111/j.1469-8137.2007.01995.x

Durme, M. V., and Nowack, M. K. (2016). Mechanisms of developmentally controlled cell death in plants. Curr. Opin. Plant Biol. 29, 29-37. doi: 10.1016/j. pbi.2015.10.013

El-Maarouf-Bouteau, H., and Bailly, C. (2008). Oxidative signaling in seed germination and dormancy. Plant Signal. Behav. 3, 175-182. doi: 10.4161/psb. 3.3.5539

El-Maarouf-Bouteau, H., Meimoun, P., Job, C., Job, D., and Bailly, C. (2013). Role of protein and mRNA oxidation in seed dormancy and germination. Front. Plant Sci. 4:77. doi: 10.3389/fpls.2013.00077

Evans, M. J., Choi, W. G., Gilroy, S., and Morris, R. (2016). A ROS-assisted calcium wave dependent on AtRBOHD and TPC1 propagates the systemic response to salt stress in Arabidopsis roots. Plant Physiol. 171, 1771-1784. doi: 10.1104/pp.16.00215

Falhof, J., Pedersen, J. T., Fuglsang, A. T., and Palmgren, M. (2016). Plasma membrane $\mathrm{H}^{+}$-ATPase regulation in the center of plant physiology. Mol. Plant 9, 323-337. doi: 10.1016/j.molp.2015.11.002

Fang, Y., Liao, K., Du, H., Xu, Y., Song, H., Li, X., et al. (2015). A stress responsive NAC transcription factor SNAC3 confers heat and drought tolerance through modulation of reactive oxygen species in rice. J. Exp. Bot. 66, 6803-6817. doi: 10.1093/jxb/erv386
Fendrych, M., Van Hautegem, T., Van Durme, M., Olvera-Carrillo, Y., Huysmans, M., Karimi, M., et al. (2014). Programmed cell death controlled by ANAC033/ SOMBRERO determines root cap organ size in Arabidopsis. Curr. Biol. 24, 931-940. doi: 10.1016/j.cub.2014.03.025

Finkelstein, R., Reeves, W., Ariizumi, T., and Steber, C. (2008). Molecular aspects of seed dormancy. Annu. Rev. Plant Biol. 59, 387-415. doi: 10.1146/annurev. arplant.59.032607.092740

Foreman, J., Demidchik, V., Bothwell, J. H., Mylona, P., Miedema, H., Torres, M. A., et al. (2003). Reactive oxygen species produced by NADPH oxidase regulate plant cell growth. Nature 422, 442-446. doi: 10.1038/nature01485

Foyer, C. H., and Noctor, G. (2005). Redox homeostasis and antioxidant signalling: a metabolic interface between stress perception and physiological responses. Plant Cell 17, 1866-1875. doi: 10.1105/tpc.105.033589

Foyer, C. H., and Noctor, G. (2013). Redox signaling in plants. Antioxid. Redox Signal. 18, 2087-2090. doi: 10.1089/ars.2013.5278

Foyer, C. H., and Noctor, G. (2016). Stress-triggered redox signalling: what's in pROSpect? Plant Cell Environ. 39, 951-964. doi: 10.1111/pce.12621

Fukuda, H. (1996). Xylogenesis: initiation, progression and cell death. Annu. Rev. Plant Physiol. Plant Mol. Biol. 47, 299-325. doi: 10.1146/annurev. arplant.47.1.299

Gadjev, I., Stone, J. M., and Gechev, T. S. (2008). Programmed cell death in plants: new insights into redox regulation and the role of hydrogen peroxide. Int. Rev. Cell Mol. Biol. 270, 87-144. doi: 10.1016/S1937-6448(08)01403-2

Gapper, C., and Dolan, L. (2006). Control of plant development by reactive oxygen species. Plant Physiol. 141, 341-345. doi: 10.1104/pp.106.079079

Gechev, T. S., Van Breusegem, F., Stone, J. M., Denev, I., and Laloi, C. (2006). Reactive oxygen species as signals that modulate plant stress responses and programmed cell death. Bioessays 28, 1091-1101. doi: 10.1002/bies.20493

Gessler, N. N., Aver'yanov, A. A., and Belozerskaya, T. A. (2007). Reactive oxygen species in regulation of fungal development. Biochemistry 72, 1091-1109.

Gill, S. S., and Tuteja, N. (2010). Reactive oxygen species and antioxidant machinery in abiotic stress tolerance in crop plants. Plant Physiol. Biochem. 48, 909-930. doi: 10.1016/j.plaphy.2010.08.016

Gilroy, S., Białasek, M., Suzuki, N., Górecka, M., Devireddy, A. R., Karpinski, S., et al. (2016). ROS, calcium, and electric signals: key mediators of rapid systemic signaling in plants. Plant Physiol. 171, 1606-1615.

Halliwell, B., and Gutteridge, J. M. C. (1989). Free Radicals in Biology and Medicine. Oxford: Clarendon Press, 450-499.

Hautegem, T. V., Waters, A. J., Goodrich, J., and Nowack, M. K. (2015). Only in dying, life: programmed cell death during plant development. Trends Plant Sci. 20, 102-113. doi: 10.1016/j.tplants.2014.10.003

Hayashi, Y., Yamada, K., Shimada, T., Matsushima, R., Nishizawa, N. K., and Nishimura, M. A. (2001). proteinase-storing body that prepares for cell death or stresses in the epidermal cells of Arabidopsis. Plant Cell Physiol. 42, 894-899. doi: $10.1093 /$ pcp/pce144

He, L., Ma, X., Li, Z., Jiao, Z., Li, Y., and Ow, D. W. (2016). Maize OXIDATIVE STRESS2 homologs enhance cadmium tolerance in Arabidopsis through activation of a putative SAM-dependent methyltransferase gene. Plant Physiol. 171, 1675-1685. doi: 10.1104/pp.16.00220

Hepler, P. K., Kunkel, J. G., Rounds, C. M., and Winship, L. J. (2012). Calcium entry into pollen tubes. Trends Plant Sci. 17, 32-38. doi: 10.1016/j.tplants.2011.10.007

Hite, D. R., Auh, C., and Scandalios, J. G. (1999). Catalase activity and hydrogen peroxide levels are inversely correlated in maize scutella during seed germination. Redox Rep. 4, 29-34. doi: 10.1179/135100099101534710

Hohl, M., Greiner, H., and Schopfer, P. (1995). The cryptic growth response of maize coleoptiles and its relationship to $\mathrm{H}_{2} \mathrm{O}_{2}$ dependent cell wall stiffening. Physiol. Plant 94, 491-498. doi: 10.1034/j.1399-3054.1995.940318.x

Holdsworth, M. J., Bentsink, L., and Soppe, W. J. (2008). Molecular networks regulating Arabidopsis seed maturation, after-ripening, dormancy and germination. New Phytol. 179, 33-54. doi: 10.1111/j.1469-8137.2008.02437.x

Huang, A. H. C., Trelease, R. N., and Moore, T. S. (1983). Plant Peroxisomes. London: Academic Press.

Huang, S., Van Aken, O., Schwarzländer, M., Belt, K., and Millar, A. H. (2016). The roles of mitochondrial reactive oxygen species in cellular signaling and stress responses in plants. Plant Physiol. 171, 1551-1559. doi: 10.1104/pp.16.00166

Hulskamp, M. (2004). Plant trichomes: a model for cell differentiation. Nat. Rev. Mol. Cell Biol. 5, 471-480. doi: 10.1038/nrm1404 
Ishibashi, Y., Koda, Y., Zheng, S. H., Yuasa, T., and Iwaya-Inoue, M. (2013). Regulation of soybean seed germination through ethylene production in response to reactive oxygen species. Ann. Bot. 111, 95-102. doi: $10.1093 / \mathrm{aob} / \mathrm{mcs} 240$

Ishibashi, Y., Tawaratsumida, T., Kondo, K., Kasa, S., Sakamoto, M., Aoki, N., et al. (2012). Reactive oxygen species are involved in gibberellin/abscisic acid signaling in barley aleurone cells. Plant Physiol. 158, 1705-1714. doi: 10.1104/pp.111.192740

Ishibashi, Y., Tawaratsumida, T., Zheng, S. H., Yuasa, T., and Iwaya-Inoue, M. (2010). NADPH oxidases act as key enzyme on germination and seedling growth in barley (Hordeum vulgare L.). Plant Prod. Sci. 13, 45-52. doi: 10.1626/pps.13.45

Ishibashi, Y., Yamamoto, K., Tawaratsumida, T., Yuasa, T., and Iwaya-Inoue, M. (2008). Hydrogen peroxide scavenging regulates germination ability during wheat (Triticum aestivum L.) seed maturation. Plant Signal. Behav. 3, 183-188. doi: $10.4161 /$ psb.3.3.5540

Jajic, I., Sarna, T., and Strzalka, K. (2015). Senescence, stress, and reactive oxygen species. Plants 4, 393-411.

Jiang, X., Gao, Y., Zhou, H., Chen, J., Wu, J., and Zhang, S. (2014). Apoplastic calmodulin promotes self-incompatibility pollen tube growth by enhancing calcium influx and reactive oxygen species concentration in Pyrus pyrifolia. Plant Cell Rep. 33, 255-263. doi: 10.1007/s00299-013-1526-y

Jomova, K., Vondrakova, D., Lawson, M., and Valko, M. (2010). Metals, oxidative stress and neurodegenerative disorders. Mol. Cell Biochem. 345, 91-104. doi: 10.1007/s11010-010-0563-X

Joo, J. H., Bae, Y. S., and Lee, J. S. (2001). Role of auxin-induced reactive oxygen species in root gravitropism. Plant Physiol. 126, 1055-1060. doi: 10.1104/pp.126.3.1055

Joo, J. H., Yoo, H. J., Hwang, I., Lee, J. S., Nam, K. H., and Bae, Y. S. (2005). Auxin-induced reactive oxygen species production requires the activation of phosphatydil linositol 3-kinase. FEBS Lett. 579, 1243-1248. doi: 10.1016/j.febslet.2005.01.018

Kalogeris, T., Bao, Y., and Korthuis, R. J. (2014). Mitochondrial reactive oxygen species: a double edged sword in ischemia/reperfusion vs preconditioning. Redox Biol. 2, 702-714. doi: 10.1016/j.redox.2014.05.006

Kapoor, D., Sharma, R., Handa, N., Kaur, H., Rattan, A., Yadav, P., et al. (2015). Redox homeostasis in plants under abiotic stress: role of electron carriers, energy metabolism mediators and proteinaceous thiols. Front. Plant Sci. 3:13. doi: $10.3389 /$ fenvs.2015.00013

Karuppanapandian, T., Moon, J. C., Kim, C., Manoharan, K., and Kim, W. (2011). Reactive oxygen species in plants: their generation, signal transduction, and scavenging mechanisms. Aust J. Crop Sci. 5, 709-725.

Kaya, H., Nakajima, R., Iwano, M., Kanaoka, M. M., Kimura, S., Takeda, S., et al. (2014). $\mathrm{Ca}^{2+}$-activated reactive oxygen species production by Arabidopsis $\mathrm{RbohH}$ and RbohJ is essential for proper pollen tube tip growth. Plant Cell 26, 1069-1080. doi: 10.1105/tpc.113.120642

Kerchev, P., Waszczak, C., Lewandowska, A., Willems, P., Shapiguzov, A., Li, Z., et al. (2016). Lack of GLYCOLATE OXIDASE1, but not GLYCOLATE OXIDASE2, attenuates the photorespiratory phenotype of CATALASE2deficient Arabidopsis. Plant Physiol. 171, 1704-1719. doi: 10.1104/pp.16. 00359

Khanna-Chopra, R. (2012). Leaf senescence and abiotic stresses share reactive oxygen species-mediated chloroplast degradation. Protoplasma 249, 469-481. doi: 10.1007/s00709-011-0308-z

Kleine, T., and Leister, D. (2016). Retrograde signaling: organelles go networking. Biochim. Biophys. Acta 1857, 1313-1325. doi: 10.1016/j.bbabio.2016. 03.017

Konrad, K. R., Wudick, M. M., and Feijó, J. A. (2011). Calcium regulation of tip growth: new genes for old mechanisms. Curr. Opin. Plant Biol. 14, 721-730. doi: 10.1016/j.pbi.2011.09.005

Laloi, C., Apel, K., and Danon, A. (2004). Reactive oxygen signalling: the latest news. Curr. Opin. Plant Biol. 7, 323-328. doi: 10.1016/j.pbi.2004.03.005

Lam, E. (2004). Controlled cell death, plant survival and development. Nat. Rev. Mol. Cell Biol. 5, 305-315. doi: 10.1038/nrm1358

Lassig, R., Gutermuth, T., Bey, T. D., Konrad, K. R., and Romeis, T. (2014). Pollen tube $\mathrm{NAD}(\mathrm{P}) \mathrm{H}$ oxidases act as a speed control to dampen growth rate oscillations during polarized cell growth. Plant J. 78, 94-106. doi: $10.1111 /$ tpj.12452
Lavenus, J., Goh, T., Roberts, I., Guyomarch, S., Lucas, M., De Smet, I., et al. (2013). Lateral root development in Arabidopsis: fifty shades of auxin. Trends Plant Sci. 18, 450-458. doi: 10.1016/j.tplants.2013.04.006

Le, C. T., Brumbarova, T., Ivanov, R., Stoof, C., Weber, E., Mohrbacher, J., et al. (2016). ZINC FINGER OF ARABIDOPSIS THALIANA12 (ZAT12) interacts with FER-LIKE IRON DEFICIENCYINDUCED TRANSCRIPTION FACTOR (FIT) linking iron deficiency and oxidative stress responses. Plant Physiol. 170, 540-557. doi: 10.1104/pp.15.01589

Lee, S., Seo, P. J., Lee, H. J., and Park, C. M. (2012). A NAC transcription factor NTL4 promotes reactive oxygen species production during drought-induced leaf senescence in Arabidopsis. Plant J. 70, 831-844. doi: 10.1111/j.1365313X.2012.04932.x

Lee, Y., Rubio, M. C., Alassimone, J., and Geldner, N. (2013). A mechanism for localized lignin deposition in the endodermis. Cell 153, 402-412. doi: 10.1016/j.cell.2013.02.045

Leymarie, J., Vitkauskaite, G., Hoang, H. H., Gendreau, E., Chazoule, V., Meimoun, P., et al. (2012). Role of reactive oxygen species in the regulation of Arabidopsis seed dormancy. Plant Cell Physiol. 53, 96-106. doi: $10.1093 / \mathrm{pcp} / \mathrm{pcr} 129$

Li, N., Zhang, D. S., Liu, H. S., Yin, C. S., Li, X. X., Liang, W. Q., et al. (2006). The rice tapetum degeneration retardation gene is required for tapetum degradation and anther development. Plant Cell 18, 2999-3014. doi: 10.1105/tpc.106. 044107

Libik-Konieczny, M., Kozieradzka-Kiszkurno, M., Desel, C., MichalecWarzecha, Z., Miszalski, Z., and Konieczny, R. (2015). The localization of NADPH oxidase and reactive oxygen species in in vitro-cultured Mesembryanthemum crystallinum L. hypocotyls discloses their differing roles in rhizogenesis. Protoplasma 252, 477-487. doi: 10.1007/s00709-0140692-2

Liszkay, A., Kenk, B., and Schopfer, P. (2003). Evidence for the involvement of cell wall peroxidase in the generation of hydroxyl radicals mediating extension growth. Planta 217, 658-667. doi: 10.1007/s00425-003-1028-1

Liu, Y., Ye, N., Liu, R., Chen, M., and Zhang, J. (2010). $\mathrm{H}_{2} \mathrm{O}_{2}$ mediates the regulation of ABA catabolism and GA biosynthesis in Arabidopsis seed dormancy and germination. J. Exp. Bot. 61, 2979-2990. doi: 10.1093/jxb/ erq125

Lovy-Wheeler, A., Kunkel, J. G., Allwood, E. G., Hussey, P. J., and Hepler, P. K. (2006). Oscillatory increases in alkalinity anticipate growth and may regulate actin dynamics in pollen tubes of lily. Plant Cell 18, 2182-2193. doi: 10.1105/tpc.106.044867

Lu, D., Wang, T., Persson, S., Mueller-Roeber, B., and Schippers, J. H. M. (2014). Transcriptional control of ROS homeostasis by KUODA1 regulates cell expansion during leaf development. Nat. commun. 5:3767. doi: 10.1038/ncomms4767

Lupini, A., Aranitia, F., Sunseri, F., and Abenavoli, M. R. (2013). Gravitropic response induced by coumarin: evidences of ROS distribution involvement. Plant Signal. Behav. 8: e23156. doi: 10.4161/psb.23156

Ma, F., Wang, L., Li, J., Samma, M. K., Xie, Y., Wang, R., et al. (2014). Interaction between HY1 and HO in auxin-induced lateral root formation in Arabidopsis. Plant Mol. Biol. 85, 49-61. doi: 10.1007/s11103-013-0168-3

Macpherson, N., Takeda, S., Shang, Z., Dark, A., Mortimer, J. C., Brownlee, C., et al. (2008). NADPH oxidase involvement in cellular integrity. Planta 227, 1415-1418. doi: 10.1007/s00425-008-0716-2

Mangano, S., Denita Juárez, S., and Estevez, J. M. (2016). ROS regulation of polar growth in plant cells. Plant Physiol. 171, 1593-1605. doi: 10.1104/pp.16.00191

Manzano, C., Pallero-Baena, M., Casimiro, I., De Rybel, B., Orman-Ligeza, B., Van Isterdael, G., et al. (2014). The emerging role of reactive oxygen species signaling during lateral root development. Plant Physiol. 165, 1105-1119. doi: $10.1104 /$ pp.114.238873

Marchi, S., Giorgi, C., Suski, J. M., Agnoletto, C., Bononi, A., Bonora, M., et al. (2012). Mitochondria-ros crosstalk in the control of cell death and aging. J. Signal Transduct. 2012:329635. doi: 10.1155/2012/329635

Marino, D., Dunand, C., Puppo, A., and Pauly, N. (2012). A burst of plant NADPH oxidases. Trends Plant Sci. 17, 9-15. doi: 10.1016/ j.tplants.2011.10.001

Marjamaa, K., Kukkola, E. M., and Fagerstedt, K. V. (2009). The role of xylem class III peroxidases in lignifications. J. Exp. Bot. 60, 367-376. doi: $10.1093 /$ jxb/ern278 
Matsuo, M., Johnson, J. M., Hieno, A., Tokizawa, M., Nomoto, M., Tada, Y., et al. (2015). High REDOX RESPONSIVE TRANSCRIPTION FACTOR1 levels result in accumulation of reactive oxygen species in Arabidopsis thaliana shoots and roots. Mol. Plant 8, 1253-1273. doi: 10.1016/j.molp.2015.03.011

Mattila, H., Khorobrykh, S., Havurinne, V., and Tyystjärvi, E. (2015). Reactive oxygen species: reactions and detection from photosynthetic tissues. J. Photochem. Photobiol. B 152 (Pt. B), 176-214. doi: 10.1016/j.jphotobiol.2015.10.001

McDonald, M. B. (1999). Seed deterioration: physiology, repair and assessment. Seed Sci. Tech. 27, 177-237.

Meir, S., Hunter, D. A., Chen, J. C., Halaly, V., and Reid, M. S. (2006). Molecular changes occurring during acquisition of abscission competence following auxin depletion in Mirabilis jalapa. Plant Physiol. 141, 1604-1616. doi: 10.1104/pp.106.079277

Messerli, M. A., and Robinson, K. R. (2007). MS channels in tip-growing systems: mechanosensitive ion channels, part A. Curr. Topic Membr. 58, 393-412. doi: 10.1016/S1063-5823(06)58015-9

Miransari, M., and Smith, D. L. (2014). Plant hormones and seed germination. Environ. Exp. Bot. 99, 110-121. doi: 10.1016/j.envexpbot.2013.11.005

Mittler, R., and Blumwald, E. (2010). Genetic engineering for modern agriculture: challenges and perspectives. Annu. Rev. Plant Biol. 61, 443-462. doi: 10.1146/annurev-arplant-042809-112116

Mittler, R., Vanderauwera, S., Suzuki, N., Miller, G., Tognetti, V. B., Vandepoele, K., et al. (2011). ROS signaling: the new wave? Trends Plant Sci. 16, 300-309. doi: 10.1016/j.tplants.2011.03.007

Moller, I. M. (2001). Plant mitochondria and oxidative stress: electron transport, NADPH turnover, and metabolism of reactive oxygen species. Annu. Rev. Plant Physiol. Plant Mol. Biol. 52, 561-591. doi: 10.1146/annurev.arplant.52. 1.561

Moller, I. M., and Sweetlove, L. J. (2010). ROS signalling - specificity is required. Trends Plant Sci. 15, 370-374. doi: 10.1016/j.tplants.2010.04.008

Monshausen, G. B., Bibikova, T. N., Messerli, M. A., Shi, C., and Gilroy, S. (2007). Oscillations in extracellular $\mathrm{pH}$ and reactive oxygen species modulate tip growth of Arabidopsis root hairs. Proc. Natl. Acad. Sci. U.S.A. 104, 20996-21001. doi: 10.1073/pnas.0708586104

Monshausen, G. B., Bibikova, T. N., Weisenseel, M. H., and Gilroy, S. (2009). Ca ${ }^{2+}$ regulates reactive oxygen species production and $\mathrm{pH}$ during mechanosensing in Arabidopsis roots. Plant Cell 21, 2341-2356. doi: 10.1105/tpc.109.068395

Monshausen, G. B., and Gilroy, S. (2009). Feeling green: mechanosensing in plants. Trends Cell Biol. 19, 228-235. doi: 10.1016/j.tcb.2009.02.005

Monshausen, G. B., Messerli, M. A., and Gilroy, S. (2008). Imaging of the Yellow Cameleon 3.6 indicator reveals that elevations in cytosolic $\mathrm{Ca}^{2+}$ follow oscillating increases in growth in root hairs of Arabidopsis. Plant Physiol. 147, 1690-1698. doi: 10.1104/pp.108.123638

Moriwaki, T., Miyazawa, Y., Kobayashi, A., Uchida, M., Watanabe, C., Fujii, N., et al. (2011). Hormonal regulation of lateral root development in Arabidopsis modulated by MIZ1 and requirement of GNOM activity for MIZ1 function. Plant physiol. 157, 1209-1220. doi: 10.1104/pp.111.186270

Müller, K., Linkies, A., Vreeburg, R. A. M., Fry, S. C., Krieger-Liszkay, A., and Luebner- Metzger, G. (2009). In vivo cell wall loosening by hydroxyl radicals during cress seed germination and elongation growth. Plant Physiol. 150, 1855-1865. doi: 10.1104/pp.109.139204

Navrot, N., Rouhier, N., Gelhaye, E., and Jacquot, J. P. (2007). Reactive oxygen species generation and antioxidant systems in plant mitochondria. Physiol. Plant 129, 185-195. doi: 10.1111/j.1399-3054.2006.00777.x

Neill, S., Desikan, R., and Hancock, J. (2002). Hydrogen peroxide signalling. Curr. Opin. Plant Biol. 5, 388-395. doi: 10.1016/S1369-5266(02)00282-0

Noctor, G., De Paepe, R., and Foyer, C. H. (2007). Mitochondrial redox biology and homeostasis in plants. Trends Plant Sci. 12, 125-134. doi: 10.1016/j.tplants.2007.01.005

Nonogaki, H. (2014). Seed dormancy and germination-emerging mechanisms and new hypotheses. Front. Plant Sci. 5:233. doi: 10.3389/fpls.2014.00233

Ogawa, K., and Iwabuchi, M. (2001). A mechanism for promoting the germination of Zinnia elegans seeds by hydrogen peroxide. Plant Cell Physiol. 42, 286-291. doi: $10.1093 / \mathrm{pcp} / \mathrm{pce} 032$

Oracz, K., El-Maarouf-Bouteau, H., Farrant, J. M., Copper, K., Belghazi, M., Job, C., et al. (2007). ROS production and protein oxidation as novel mechanism of seed dormancy alleviation. Plant J. 50, 452-465. doi: 10.1111/j.1365313X.2007.03063.x

Palma, J. M., Corpas, F. J., and del Rio, L. A. (2009). Proteome of plant peroxisomes: new perspectives on the role of these organelles in cell biology. Proteomics 9 , 2301-2312. doi: 10.1002/pmic.200700732

Panavas, T., and Rubinstein, B. (1998). Oxidative events during programmed cell death of daylily (Hemerocallis hybrid) petals. Plant Sci. 133, 125-138. doi: 10.1016/S0168-9452(98)00034-X

Passaia, G., Queval, G., Bai, J., Margis-Pinheiro, M., and Foyer, C. H. (2014). The effects of redox controls mediated by glutathione peroxidases on root architecture in Arabidopsis thaliana. J. Exp. Bot. 65, 1403-1413. doi: 10.1093/jxb/ert486

Passardi, F., Penel, C., and Dunand, C. (2004). Performing the paradoxical: how plant peroxidases modify the cell wall. Trends Plant Sci. 9, 534-540. doi: 10.1016/j.tplants.2004.09.002

Petrasek, J., and Friml, J. (2009). Auxin transport routes in plant development. Development 136, 2675-2688. doi: 10.1242/dev.030353

Petrov, V., Hille, J., Mueller-Roeber, B., and Gechev, T. S. (2015). ROS-mediated abiotic stress-induced programmed cell death in plants. Front. Plant Sci. 6:69. doi: 10.3389/fpls.2015.00069

Petrov, V. D., and Van Breusegem, F. (2012). Hydrogen peroxide - a central hub for information flow in plant cells. AoB Plants 2012, 1s014. doi: 10.1093/aobpla/pls014

Pierson, E. S., Miller, D. D., Callaham, D. A., Shipley, A. M., Rivers, B. A., Cresti, M., et al. (1994). Pollen tube growth is coupled to the extracellular calcium ion flux and the intracellular calcium gradient: effect of BAPTAtype buffers and hypertonic media. Plant Cell 6, 1815-1828. doi: 10.2307/3869910

Plackett, A. R. G., Thomas, S. G., Wilson, Z. A., and Hedden, P. (2011). Gibberellin control of stamen development: a fertile field. Trends Plant Sci. 16, 568-578. doi: 10.1016/j.tplants.2011.06.007

Pospisil, P. (2012). Molecular mechanisms of production and scavenging of reactive oxygen species by photosystem II. Biochimi Biophys. Acta 1817, 218231. doi: 10.1016/j.bbabio.2011.05.017

Potikha, T. S., Collins, C. C., Johnson, D. I., Delmer, D. P., and Levine, A. (1999). The involvement of hydrogen peroxide in the differentiation of secondary walls in cotton fibers. Plant Physiol. 119, 849-858. doi: 10.1104/pp.119.3.849

Prasad, S. M., Kumar, S., Parihar, P., Singh, A., and Singh, R. (2015). Evaluating the combined effects of pretilachlor and UV-B on two Azolla species. Pesti. Biochem. Physiol. 128, 45-56. doi: 10.1016/j.pestbp.2015.10.006

Puntarulo, S., Sanchez, R. A., and Boveris, A. (1988). Hydrogen peroxide metabolism in soybean embryonic axes at the onset of germination. Plant Physiol. 86, 626-630. doi: 10.1104/pp.86.2.626

Punwani, J. A., Rabiger, D. S., and Drews, G. N. (2007). MYB98 positively regulates a battery of synergid-expressed genes encoding filiform apparatus localized proteins. Plant Cell 19, 2557-2568. doi: 10.1105/tpc.107.052076

Qin, Y., and Yang, Z. (2011). Rapid tip growth: insights from pollen tubes. Semin. Cell Dev. Biol. 22, 816-824. doi: 10.1016/j.semcdb.2011.06.004

Rajhi, I., Yamauchi, T., Takahashi, H., Nishiuchi, S., Shiono, K., Watanabe, R., et al. (2011). Identification of genes expressed in maize root cortical cells during lysigenous aerenchyma formation using laser microdissection and microarray analyses. New Phytol. 190, 351-368. doi: 10.1111/j.1469-8137.2010.03535.x

Rentel, M. C., and Knight, M. R. (2004). Oxidative stress-induced calcium signaling in Arabidopsis. Plant Physiol. 135, 1471-1479. doi: 10.1104/pp.104.042663

Rhoads, D. M., Umbach, A. L., Subbaiah, C. C., and Siedow, J. N. (2006). Mitochondrial reactive oxygen species. Contribution to oxidative stress and interorganellar signaling. Plant Physiol. 141, 357-366.

Roberts, K., and McCann, M. C. (2000). Xylogenesis: the birth of a corpse. Curr. Opin. Plant Biol. 3, 517-522. doi: 10.1016/S1369-5266(00)00122-9

Rodríguez-Serrano, M., Romero-Puertas, M. C., Sanz-Fernández, M., Hu, J., and Sandalio, L. M. (2016). Peroxisomes extend peroxules in a fast response to stress via a reactive oxygen species-mediated induction of the peroxin PEX11a. Plant Physiol. 171, 1665-1674. doi: 10.1104/pp.16.00648

Ros Barceló, A. (2005). Xylem parenchyma cells deliver the $\mathrm{H}_{2} \mathrm{O}_{2}$ necessary for lignification in differentiating xylem vessels. Planta 220, 747-756. doi: 10.1007/s00425-004-1394-3

Rubio-Diaz, S., Perez-Perez, J. M., Gonzalez-Bayon, R., Munoz-Viana, R., Borrega, N., Mouille, G., et al. (2012). Cell expansion-mediated organ growth 
is affected by mutations in three EXIGUA genes. PLOS ONE 7:e36500. doi: 10.1371/journal.pone.0036500

Sagi, M., and Fluhr, R. (2006). Production of reactive oxygen species by plant NADPH oxidases. Plant Physiol. 141, 336-340. doi: 10.1104/pp.106.078089

Sakamoto, M., Munemura, I., Tomita, R., and Kobayashi, K. (2008). Reactive oxygen species in leaf abscission signaling. Plant Signal. Behav. 3, 1014-1015. doi: $10.4161 /$ psb. 6737

Sandalio, L. M., Rodríguez-Serrano, M., Romero-Puertas, M. C., and del Rio, L. A. (2013). Role of peroxisomes as a source of reactive oxygen species (ROS) signalling molecules. Subcell. Biochem. 69, 231-255. doi: 10.1007/978-94-0076889-5_13

Schopfer, P. (1996). Hydrogen peroxide-mediated cell-wall stiffening in vitro in maize coleoptiles. Planta 199, 43-49. doi: 10.1007/BF00196879

Schopfer, P., Liszkay, A., Bechtold, M., Frahry, G., and Wagner, A. (2002). Evidence that hydroxyl radicals mediate auxin-induced extension growth. Planta 214, 821-828. doi: 10.1007/s00425-001-0699-8

Schopfer, P., Plachy, C., and Frahry, G. (2001). Production of reactive oxygen intermediates (superoxide radicals, hydrogen peroxide, and hydroxyl radicals) and peroxidase in germinating radish seeds controlled by light, gibberellin, and abscisic acid. Plant Physiol. 125, 1591-1602. doi: 10.1104/pp.125.4.1591

Schweikert, C., Liszkay, A., and Schopfer, P. (2000). Scission of polysaccharides by peroxidase-generated hydroxyl radicals. Phytochemistry 53, 562-570. doi: 10.1016/S0031-9422(99)00586-5

Serrano, I., María, C., Romero-Puertas, Sandalio, L. M., and Olmedilla, A. (2015). The role of reactive oxygen species and nitric oxide in programmed cell death associated with self-incompatibility. J. Exp. Bot. 66, 2869-2876. doi: $10.1093 / \mathrm{jxb} / \mathrm{erv} 083$

Serrano, I., and Olmedilla, A. (2012). Histochemical location of key enzyme activities involved in receptivity and self-incompatibility in the olive tree (Olea europaea L.). Plant Sci. 197, 40-49. doi: 10.1016/j.plantsci.2012.07.007

Serrano, I., Romero-Puertas, M. C., Rodríguez-Serrano, M., Sandalio, L. M., and Olmedilla, A. (2012). Peroxynitrite mediates programmed cell death both in papillar cells and in self-incompatible pollen in the olive (Olea europaea L.). J. Exp. Bot. 63, 1479-1493. doi: 10.1093/jxb/err392

Sharma, P., Jha, A. B., Dubey, R. S., and Pessarakli, M. (2012). Reactive oxygen species, oxidative damage and anti-oxidative defense mechanism in plants under stressful conditions. J. Bot. 2012, 1-26. doi: 10.1155/2012/217037

Singh, S., Ambasth, V., Levine, A., Sopory, S. K., Yadava, P. K., Tripathy, B. C., et al. (2015). Anhydrobiosis and programmed cell death in plants: Commonalities and Differences. Curr. Plant Biol. 2, 12-20. doi: 10.1016/j.cpb.2014.12.001

Singh, V. P., Singh, S., Kumar, J., and Prasad, S. M. (2015a). Hydrogen sulfide alleviates toxic effects of arsenate in pea seedlings through up-regulation of the ascorbate-glutathione cycle: possible involvement of nitric oxide. J. Plant Physiol. 181, 20-29. doi: 10.1016/j.jplph.2015.03.015

Singh, V. P., Singh, S., Kumar, J., and Prasad, S. M. (2015b). Investigating the roles of ascorbate-glutathione cycle and thiol metabolism in arsenate tolerance in ridged Luffa seedlings. Protoplasma 252, 1217-1229. doi: 10.1007/s00709-0140753-6

Singh, V. P., Srivastava, P. K., and Prasad, S. M. (2012a). Differential effect of UV$\mathrm{B}$ radiation on growth, oxidative stress and ascorbate-glutathione cycle in two cyanobacteria under copper toxicity. Plant Physiol. Biochem. 61, 61-70. doi: 10.1016/j.plaphy.2012.09.005

Singh, V. P., Srivastava, P. K., and Prasad, S. M. (2012b). UV-B induced differential effect on growth and nitrogen metabolism in two cyanobacteria under copper toxicity. Cell Mol. Biol. 58, 81-91.

Spartz, A. K., Ren, H., Park, M. Y., Grandt, K. N., Lee, S. H., Murphy, A. S., et al. (2014). SAUR inhibition of PP2C-D phosphatases activates plasma membrane $\mathrm{H}^{+}$-ATPases to promote cell expansion in Arabidopsis. Plant Cell 26, 21292142. doi: 10.1105/tpc.114.126037

Springer, A., Acker, G., Bartsch, S., Bauerschmitt, H., Reinbothe, S., and Reinbothe, C. (2015). Differences in gene expression between natural and artificially induced leaf senescence in barley. J. Plant Pysiol. 176, 180-191. doi: 10.1016/j.jplph.2015.01.004

Steffens, B. (2014). The role of ethylene and ROS in salinity, heavy metal, and flooding responses in rice. Front. Plant Sci. 5:685. doi: 10.3389/fpls.2014.00685

Steffens, B., Geske, T., and Sauter, M. (2011). Aerenchyma formation in the rice stem and its promotion by $\mathrm{H}_{2} \mathrm{O}_{2}$. New Phytol. 190, 369-378. doi: 10.1111/j.1469-8137.2010.03496.x
Steffens, B., and Sauter, M. (2009). Epidermal cell death in rice is confined to cells with a distinct molecular identity and is mediated by ethylene and $\mathrm{H}_{2} \mathrm{O}_{2}$ through an autoamplified signal pathway. Plant Cell 21, 184-196. doi: $10.1105 /$ tpc. 108.061887

Steinhorst, L., and Kudla, J. (2013). Calcium-A central regulator of pollen germination and tube growth. Biochim. Biophys. Acta 1833, 1573-1581. doi: 10.1016/j.bbamcr.2012.10.009

Stern, R., Kogan, G., Jedrzejas, M. J., and Soltés, L. (2007). The many ways to cleave hyaluronan. Biotechnol. Adv. 25, 537-557. doi: 10.1016/j.biotechadv. 2007.07.001

Sundaravelpandian, K., Chandrika, N. N., and Schmidt, W. (2013). PFT1, a transcriptional Mediator complex subunit, controls root hair differentiation through reactive oxygen species (ROS) distribution in Arabidopsis. New Phytol. 197, 151-161. doi: 10.1111/nph.12000

Suzuki, N., Koussevitzky, S., Mittler, R., and Miller, G. (2012). ROS and redox signalling in the response of plants to abiotic stress. Plant Cell Environ. 35, 259-270. doi: 10.1111/j.1365-3040.2011.02336.x

Suzuki, N., Miller, G., Salazar, C., Mondal, H. A., Shulaev, E., Cortes, D. F., et al. (2013). Temporal-spatial interaction between reactive oxygen species and abscisic acid regulates rapid systemic acclimation in plants. Plant Cell 25, 3553-3569. doi: 10.1105/tpc.113.114595

Swanson, S., and Gilroy, S. (2010). ROS in plant development. Physiol. Plant 138, 384-392. doi: 10.1111/j.1399-3054.2009.01313.x

Takagi, D., Takumi, S., Hashiguchi, M., Sejima, T., and Miyake, C. (2016). Superoxide and singlet oxygen produced within the thylakoid membranes both cause photosystem I photoinhibition. Plant Physiol. 171, 1626-1634. doi: $10.1104 /$ pp. 16.00246

Tanioka, S., Matsui, Y., Irie, T., Tanigawa, T., Tanaka, Y., Shibata, H., et al. (1996). Oxidative depolymerization of chitosan by hydroxyl radical. Biosci. Biotechnol. Biochem. 60, 2001-2004. doi: 10.1371/journal.pone.0100743

Thomas, H. (2013). Senescence, ageing and death of the whole plant. New Phytol. 197, 696-711. doi: 10.1111/nph.12047

Townsley, B. T., and Sinha, N. R. (2012). A new development: evolving concepts in leaf ontogeny. Annu. Rev. Plant Biol. 63, 535-562. doi: 10.1146/annurevarplant-042811-105524

Tripathi, S. K., and Tuteja, N. (2007). Integrated signaling in flower senescence. Plant Signal. Behav. 2, 437-445. doi: 10.4161/psb.2.6.4991

Tsukagoshi, H., Busch, W., and Benfey, P. N. (2010). Transcriptional regulation of ROS controls transition from proliferation to differentiation in the root. Cell 143, 606-616. doi: 10.1016/j.cell.2010.10.020

van Doorn, W. G., Beers, E. P., Dangl, J. L., Franklin-Tong, V. E., Gallois, P., HaraNishimura, I., et al. (2011). Morphological classification of plant cell deaths. Cell Death Differ. 18, 1241-1246. doi: 10.1038/cdd.2011.36

Vanacker, H., Sandalio, L. M., Jimenez, A., Palma, J. M., Corpas, F. J., Meseguer, V., et al. (2006). Role of redox regulation in leaf senescence of pea plants grown in different sources of nitrogen nutrition. J. Exp. Bot. 57, 1735-1745. doi: $10.1093 / \mathrm{jxb} / \mathrm{erl} 012$

Vertucci, C. W., and Farrant, J. M. (1995). “Acquisition and loss of desiccation tolerance," in Seed Development and Germination, eds J. Kigel and G. Galili (New York, NY: Marcel Dekker), 237-271.

Vogel, M. O., Moore, M., König, K., Pecher, P., Alsharafa, K., Lee, J., et al. (2014). Fast retrograde signaling in response to high light involves metabolite export, MITOGEN-ACTIVATED PROTEIN KINASE6, and AP2/ERF transcription factors in Arabidopsis. Plant Cell 26, 1151-1165. doi: 10.1105/tpc.113. 121061

Wang, C. L., and Zhang, S. L. (2011). A cascade signal pathway occurs in self-incompatibility of Pyrus pyrifolia. Plant Signal. Behav. 6, 420-421. doi: 10.4161/psb.6.3.14386

Wang, Y., Loake, G. J., and Chu, C. (2013). Cross talk of nitric oxide and reactive oxygen species in plant programmed cell death. Front. Plant Sci. 4:314. doi: 10.3389/fpls.2013.00314

Wells, D. M., Wilson, M. H., and Bennett, M. J. (2010). Feeling UPBEAT about growth: linking ROS gradients and cell proliferation. Dev. Cell 19, 644-646. doi: 10.1016/j.devcel.2010.10.017

Wilkins, K. A., Bancroft, J., Bosch, M., Ings, J., Smirnoff, N., and FranklinTong, V. E. (2011). Reactive oxygen species and nitric oxide mediate actin reorganization and programmed cell death in the selfincompatibility response of Papaver. Plant Physiol. 156, 404-416. doi: 10.1104/pp.110.167510 
Wilkins, K. A., Bosch, M., Haque, T., Teng, N., Poulter, N. S., and FranklinTong, V.E. (2015). Self-incompatibility-induced programmed cell death in field poppy pollen involves dramatic acidification of the incompatible pollen tube cytosol. Plant Physiol. 167, 766-779. doi: 10.1104/pp.114.252742

Willems, P., Mhamdi, A., Stael, S., Storme, V., Kerchev, P., Noctor, G., et al. (2016). The ROS wheel: refining ROS transcriptional footprints in Arabidopsis. Plant Physiol. 171, 1720-1733. doi: 10.1104/pp.16.00420

Wolf, S., and Höfte, H. (2014). Growth control: a saga of cell walls, ROS, and peptide receptors. Plant Cell 26, 1848-1856.

Wong, H. L., Sakamoto, T., Kawasaki, T., Umemura, K., and Shimamoto, K. (2004). Down-regulation of metallothionein, a reactive oxygen scavenger, by the small GTPase OsRac1 in rice. Plant Physiol. 135, 1447-1456. doi: 10.1104/pp.103.036384

Wrzaczek, M., Brosche, M., and Kangasjarvi, J. (2013). ROS signaling loops: production, perception, regulation. Curr. Opin. Plant Biol. 16, 575-582. doi: 10.1016/j.pbi.2013.07.002

Wu, G., Shortt, B. J., Lawrence, E. B., Leon, J., Fitzsimmons, K. C., Levine, E. B., et al. (1997). Activation of host defense mechanisms by elevated production of $\mathrm{H}_{2} \mathrm{O}_{2}$ in transgenic plants. Plant Physiol. 115, 427-435.

Wu, J., Shang, Z., Jiang, X., Moschou, P. N., Sun, W., Roubelakis-Angelakis, K. A., et al. (2010). Spermidine oxidase-derived $\mathrm{H}_{2} \mathrm{O}_{2}$ regulates pollen plasma membrane hyperpolarization-activated $\mathrm{Ca}^{2+}$-permeable channels and pollen tube growth. Plant J. 63, 1042-1053. doi: 10.1111/j.1365-313X.2010.04301.x

Xie, H. T., Wan, Z. Y., Li, S., and Zhang, Y. (2014). Spatiotemporal production of reactive oxygen species by NADPH oxidase is critical for tapetal programmed cell death and pollen development in Arabidopsis. Plant Cell 26, 2007-2023. doi: $10.1105 /$ tpc. 114.125427

Xu, J., Yin, H., Li, Y., and Liu, X. (2010). Nitric oxide is associated with longterm zinc tolerance in Solanum nigrum. Plant Physiol. 154, 1319-1334. doi: $10.1104 /$ pp. 110.162982
$\mathrm{Xu}, \mathrm{R}$, and Li, Y. (2011). Control of final organ size by mediator complex subunit 25 in Arabidopsis thaliana. Development 138, 4545-4554. doi: $10.1242 /$ dev.071423

Yadegari, R., and Drews, G. N. (2004). Female gametophyte development. Plant Cell 16, S133-S141. doi: 10.1105/tpc.018192

Ye, N., Zhu, G., Liu, Y., Zhang, A., Li, Y., Liu, R., et al. (2012). Ascorbic acid and reactive oxygen species are involved in the inhibition of seed germination by abscisic acid in rice seeds. J. Exp. Bot. 63, 1809-1822. doi: 10.1093/jxb/err336

Zafra, A., Rodríguez-García, M. I., and Alché, J. D. (2010). Cellular localization of ROS and NO in olive reproductive tissues during flower development. $B M C$ Plant Biol. 10:36. doi: 10.1186/1471-2229-10-36

Zhang, L., Ren, F., Zhang, Q., Chen, Y., Wang, B., and Jiang, J. (2008). The TEAD/TEF family of transcription factor Scalloped mediates Hippo signaling in organ size control. Dev. Cell 14, 377-387. doi: 10.1016/j.devcel.2008.01.006

Zhu, Y., Yan, J., Liu, W., Liu, L., Sheng, Y., Sun, Y., et al. (2016). Phosphorylation of a NAC transcription factor by ZmCCaMK regulates abscisic acidinduced antioxidant defense in maize. Plant Physiol. 171, 1651-1664. doi: 10.1104/pp. 16.00168

Conflict of Interest Statement: The authors declare that the research was conducted in the absence of any commercial or financial relationships that could be construed as a potential conflict of interest.

Copyright (c) 2016 Singh, Singh, Parihar, Mishra, Tripathi, Singh, Chauhan and Prasad. This is an open-access article distributed under the terms of the Creative Commons Attribution License (CC BY). The use, distribution or reproduction in other forums is permitted, provided the original author(s) or licensor are credited and that the original publication in this journal is cited, in accordance with accepted academic practice. No use, distribution or reproduction is permitted which does not comply with these terms. 